Pontifícia Universidade Católica do Rio de Janeiro

O impacto da marca na decisão de compra do consumidor: uma avaliação do setor de smartphones

Pedro Henrique Pau Brasil Salles

Trabalho de Conclusão de Curso

Centro de Ciências Socials - CCS

Departamento de Administração

Graduação em Administração de Empresas 
Pedro Henrique Pau Brasil Salles

\section{O impacto da marca na decisão de compra do consumidor: uma avaliação do setor de smartphones}

Trabalho de Conclusão de Curso

Trabalho de Conclusão de Curso, apresentado ao programa de graduação em Administração da PUC-Rio como requisito parcial para a obtenção do título de graduação em Administração.

Orientador: Daniel Kamlot

Rio de Janeiro, novembro de 2019. 
"Uma marca não é mais o que nós dizemos para os consumidores, mas sim o que eles dizem uns aos outros que é" - Scott Cook (presidente da Intuit e membro do conselho do eBay e da $P \& G$ ) 


\section{Agradecimentos}

Agradeço primeiramente aos meus pais Selma e Fernando por terem sempre me proporcionado a melhor educação que eles puderam e por todo o apoio que me deram ao longo da vida. Ademais, gostaria de agradecer ao meu padrasto Jorge por ter me proporcionado a realização de minha graduação na PUC-Rio, sem ele isso não seria possível.

Além disso, gostaria de agradecer minha irmã e melhor amiga Juliana, minha avó Judith, minha dinda Lygia e meu cunhado Phelipe por sempre estarem ao meu lado e por me orientarem em todos os momentos e também a todos os familiares que de alguma forma estiveram ao meu lado ao longo de minha trajetória.

À minha avó Margarida por ter sido uma pessoa incrível enquanto esteve ao meu lado e tenho certeza de que ela vai estar sempre comigo, no meu coração.

À minha namorada e fiel companheira Beatriz, que sempre esteve ao meu lado durante toda a minha trajetória acadêmica e me apoiou nos momentos mais difíceis e indubitavelmente foi essencial para mais essa conquista na minha vida. $E$ também à sua família, por todo o suporte e conselhos.

Obrigado também a todos os professores da PUC-Rio que me ajudaram e proporcionaram muito aprendizado ao longo de toda trajetória acadêmica, em especial, Sylvia e Martim.

Agradeço bastante ao meu orientador Daniel Kamlot, por todos os ensinamentos, apoio, dedicação e paciência no processo de elaboração do presente trabalho. Sem ele, tenho certeza que meu trabalho não teria a mesma qualidade.

Por fim, agradeço aos amigos que fiz na faculdade e que estiveram ao meu lado em todos esses anos de graduação, em especial, Gabriel e Victor Paulo. 


\section{Resumo}

Salles, Pedro. O impacto da marca na decisão de compra do consumidor: uma avaliação do setor de smartphones. Rio de janeiro, 2019. 49 p. Trabalho de Conclusão de Curso - Departamento de Administração. Pontifícia Universidade Católica do Rio de Janeiro.

O trabalho foi realizado com o objetivo de analisar a opinião dos consumidores das marcas Apple, Samsung, Motorola e LG, no setor de smartphones, em relação ao grau de impacto da marca na sua decisão de compra. Foram exploradas diversas abordagens teóricas da área de marketing, para analisar a relevância de vários fatores, como marca, brand equity, comportamento do consumidor, percepção, entre outros. Para realizar a análise foi utilizado uma pesquisa quantitativa no formato de questionário, utilizando uma adaptação da escala multidimensional de brand equity, desenvolvida por Yoo e Donthu (2001). Os resultados obtidos indicam as variações nas opiniões dos respondentes, dependendo de qual marca de smartphone eles são clientes, em relação a importância da marca no processo decisório de compra.

\section{Palavras-chave:}

Brand equity, comportamento do consumidor, consumidores, decisão de compra do consumidor, escala multidimensional de brand equity, fidelidade, marca, marketing, percepção, smartphones. 


\section{Abstract}

Salles, Pedro. The impact of the brand in the consumer decision process: a smartphone industry assessment. Rio de Janeiro, 2019. 49 p. Course Conclusion Paper - Department of Administration. Pontifical Catholic University of Rio de Janeiro.

This paper was done with the objective of analyze the opinion of the consumers of the brands Apple, Samsung, Motorola and LG, in the smartphone industry, about the impact degree of the brand in their buying decision. Several theoretical approaches of the marketing area were explored to analyze the relevance of a lot of factors, as brand, brand equity, consumer behavior, perception, among others. To perform the analyze it was used a quantitative research in quiz format, using an adaptation of the multidimensional brand equity scale, developed by Yoo and Donthu (2001). The obtained results indicate the variations in the opinions of the respondents, depending of which smartphone brand they are clients, regarding the importance of the brand in the buying decision process.

\section{Key words:}

Brand, brand equity, buying decision of the consumer, consumer behavior, consumers, faithfulness, marketing, multidimensional brand equity scale, perception, smartphones. 


\section{Sumário}

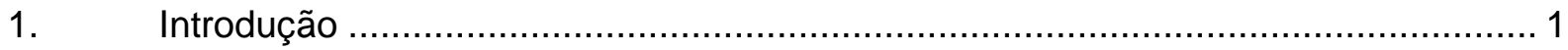

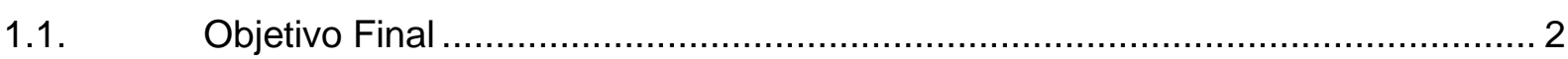

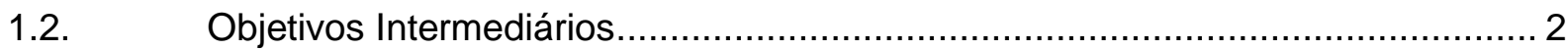

1.3. Delimitação do Estudo …........................................................................ 3

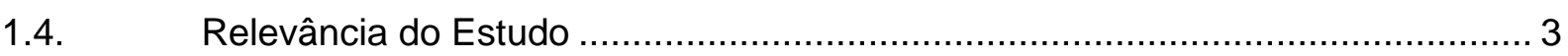

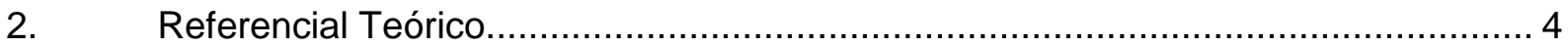

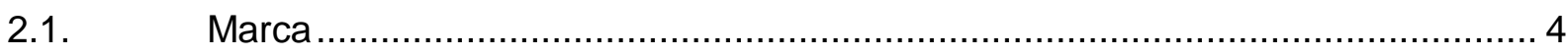

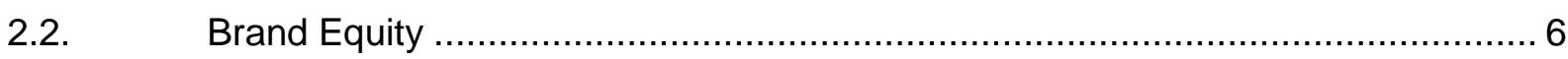

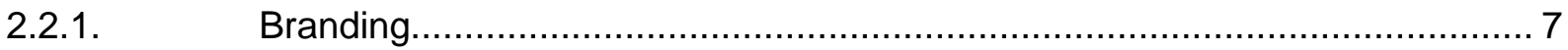

2.2.2. Escala Multidimensional de Brand Equity de Yoo e Donthu (2001) .............. 8

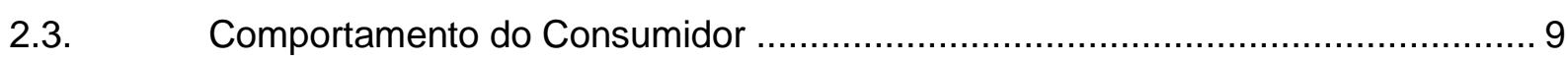

2.3.1. Decisão de Compra do Consumidor......................................................... 11

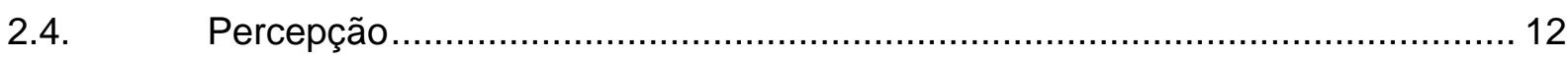

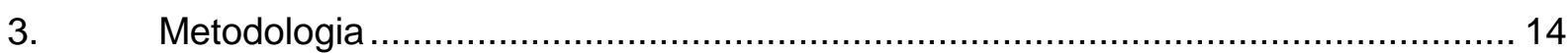

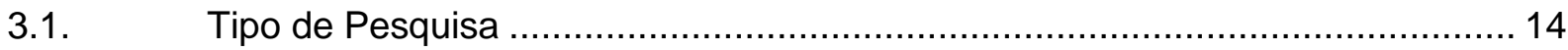

3.2. Universo e Amostra .......................................................................... 14

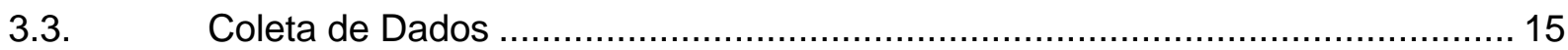

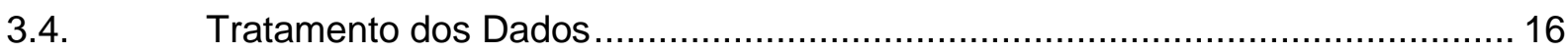

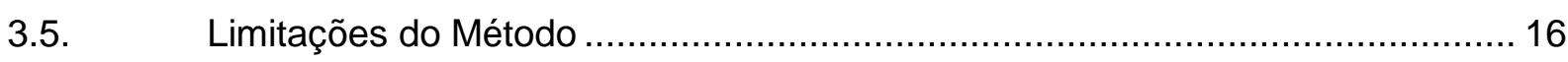

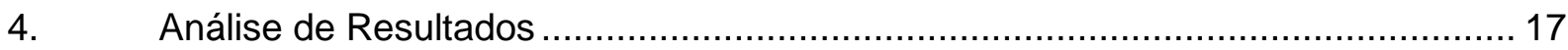

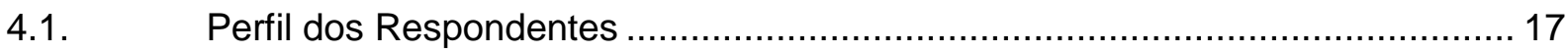

4.2. Critérios Importantes na Decisão de Compra .............................................. 20

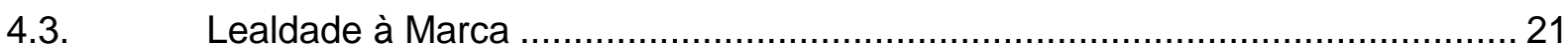

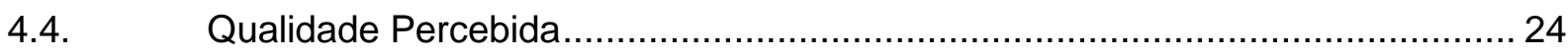

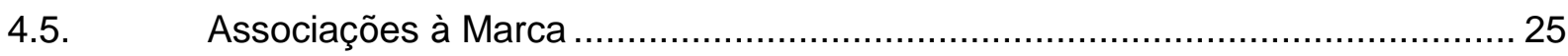




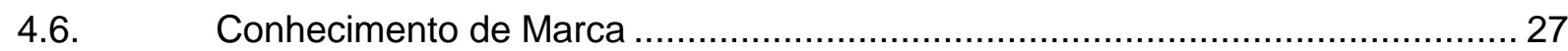

4.7. $\quad$ Avaliação da Importância da Marca .......................................................... 28

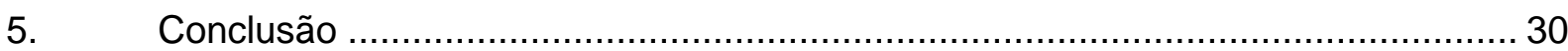

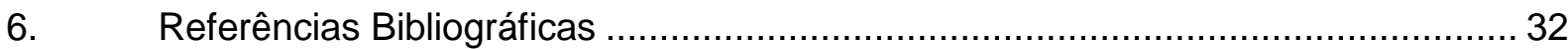

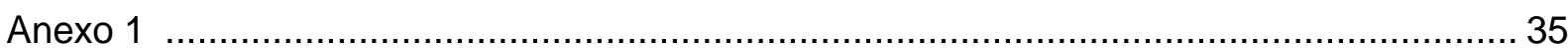

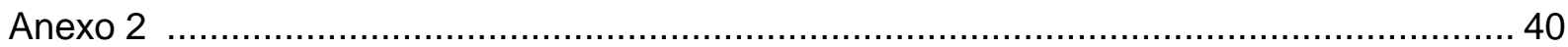

\section{Lista de figuras}

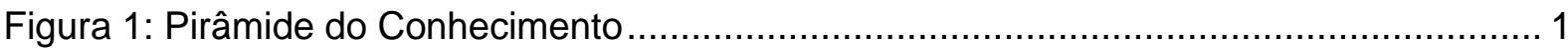

Figura 2: Pirâmide de Construção de Brand Equity ...................................................... 5

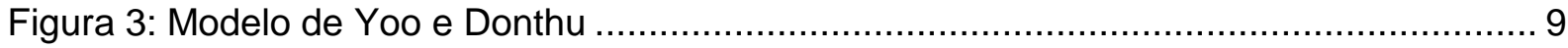

\section{Lista de gráficos}

Gráfico 1: Marcas do Smartphones dos Respondentes ............................................... 17

Gráfico 2: Faixa Etária dos Respondentes.................................................................... 18

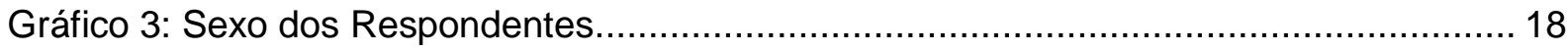

Gráfico 4: Nível de Escolaridade dos Respondentes .................................................. 19

Gráfico 5: Renda Familiar dos Respondentes........................................................ 20

Gráfico 6: Tempo de Uso de Smartphone da mesma Marca, pelos Respondentes ............. 22

Gráfico 7: Opinião dos Respondentes em se Considerarem Fiéis a Marca de seu

Smartphone

Gráfico 8: Opinião dos Respondentes sobre a sua Marca de Smartphone ser sua Primeira

Opção de Compra

Gráfico 9: Opinião dos Respondentes sobre Possibilidade de Não Trocar de Marca de Smartphone

Gráfico 10: Opinião dos Respondentes quanto a Percepção de Qualidade de seu

Smartphone 
Gráfico 11: Opinião dos Respondentes sobre Lembrar das Características de seus Smartphones 26

Gráfico 12: Opinião dos Respondentes sobre a Lembrança do Logo ou Símbolo do seu Smartphone.....

Gráfico 13: Percepção dos Respondentes sobre Conhecimento da Marca de seu Smartphone 28

Gráfico 14: Opinião dos Respondentes sobre Importância da Avaliação da Marca no Setor de Smartphones. 29

\section{Lista de tabelas}

Tabela 1: Critérios Importantes da Decisão de Compra do Consumidor 


\section{Introdução}

Segundo a fala de Stephen King (apud AAKER, 1991, p.16), em um evento no WPP Group (empresa britânica de publicidade e relações públicas), em Londres:

O produto é algo que é feito na fábrica; a marca é algo que é comprado pelo consumidor. O produto pode ser copiado pelo concorrente; a marca é única. O produto pode ficar ultrapassado rapidamente; a marca bem-sucedida é eterna.

Com base nessa citação, é inquestionável a importância de ter uma marca reconhecida para que esta seja preferência dos consumidores e seja vista como uma marca top of mind, ou seja, aquela que vem em primeiro lugar na mente do consumidor quando ele pensa no setor em que tal marca está inserida (AAKER, 1998). E isso é um fator essencial na decisão de compra de algum produto ou serviço, portanto, a percepção do cliente sobre a marca é algo que precisa ser trabalhado para ser positivo e, assim, gerar lealdade. Ademais, conforme ilustrado na figura 1, existem quatro estágios na pirâmide do conhecimento (desconhecimento da marca, reconhecimento da marca, lembrança de marca e top of mind), porém o nível que as empresas visam alcançar é justamente o top of mind, uma posição especial e que está à frente das outras marcas na lembrança do indivíduo (AAKER, 1998).

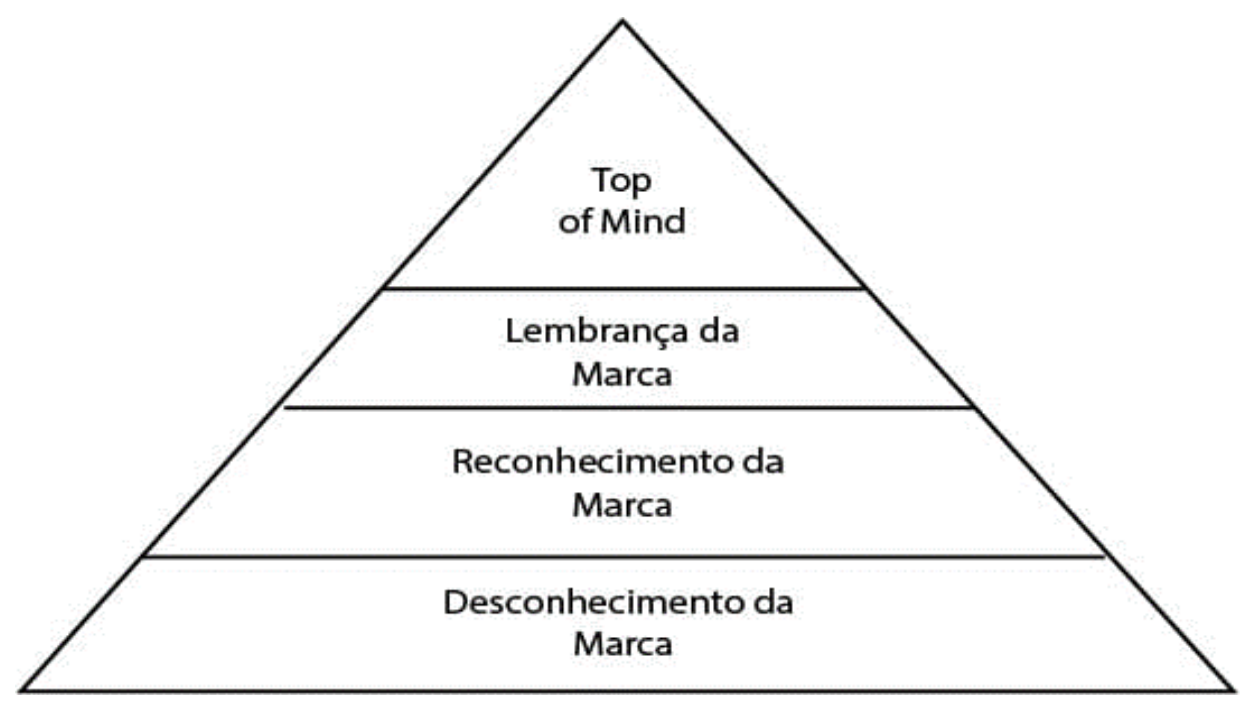

Figura 1: Pirâmide do Conhecimento

Fonte: Aaker (1998) 
No setor de smartphones, a marca é um fator que afeta as decisões de compra dos consumidores e existe uma tendência de comprar sempre os aparelhos da marca que mais os agradam, ou seja, se eles costumam comprar os celulares da Samsung, por exemplo, provavelmente seguirão consumindo tal.

No Brasil, as quatro principais marcas do setor detêm em torno de $86 \%$ do mercado, sendo a Samsung com 40,35\%, seguida de Motorola com 24,23\%, Apple com 13\% e LG com 8,42\% (STATCOUNTER, 2019). Isso demonstra que é um mercado hegemônico, em que poucas empresas dominam o segmento.

Ademais, segundo um levantamento global realizado pelo IAB Brasil - Interactive Advetising Bureau (2017), 38\% dos brasileiros usam o smartphone por seis horas ou mais diariamente, enquanto a média mundial é de $22 \%$ e isso mostra que os dispositivos móveis estão cada vez mais presentes no cotidiano das pessoas, principalmente, os smartphones, que segundo uma pesquisa realizada pela Deloitte (2018), correspondem ao dispositivo com maior acesso pelos usuários de telefonia móvel no Brasil no último ano (92\%). Também, de acordo com uma análise de mercado feita pela Counterpoint (2018), esse setor apresentou um aumento de $2,3 \%$, com uma perspectiva positiva de crescimento.

Por fim, levando em conta a importância das marcas e o crescente uso de smartphones no Brasil, qual o grau de impacto que elas possuem na decisão de compra dos consumidores?

\subsection{Objetivo Final}

O objetivo final deste estudo é avaliar o grau de impacto que a marca possui na decisão de compra dos consumidores no setor de smartphones a partir da avaliação do brand equity. Ademais, será estudado se a mesma interfere mais na compra do celular do que suas próprias funcionalidades.

\subsection{Objetivos Intermediários}

Visando alcançar o objetivo final, este estudo prevê alcançar os seguintes objetivos intermediários:

1) Identificar os critérios mais relevantes para os consumidores ao comprar um smartphone;

2) Identificar os elementos do brand equity que tem alguma influência na decisão de compra no setor de smartphones; 
3) Analisar se nesse setor a boa avaliação da marca é determinante para a compra do produto.

\subsection{Delimitação do Estudo}

O foco do trabalho estará em analisar o setor de smartphones no Brasil e as marcas mais utilizadas pelos consumidores no mercado brasileiro, isto é, Samsung, Motorola, Apple e LG.

O estudo se delimitará ao público jovem (de faixa etária entre 18 e 31 anos), que residam no Rio de Janeiro e consumam smartphones das marcas supracitadas.

\subsection{Relevância do Estudo}

No ramo empresarial, é de suma importância para as empresas entenderem o quão essencial é ter uma marca com uma boa imagem no mercado e como isso impacta no processo de decisão de compra dos consumidores e o retorno financeiro gerado através disso. Ademais, o estudo possui também relevância para as mesmas conhecerem a percepção dos consumidores sobre sua marca, logo, é importante para os detentores dessas marcas.

Além disso, para o meio acadêmico, o estudo irá colaborar com estudiosos do tema que buscam entender a importância que a marca possui no processo de decisão de compra dos consumidores, pois será estudado o grau de impacto que as marcas possuem no momento de comprar um smartphone no mercado brasileiro.

Por fim, com o presente estudo, mostra-se para os indivíduos o poder que as marcas possuem em suas vidas e como impactam em suas decisões de compra, em especial, no mercado de smartphones. Muitas vezes deixamos de consumir um celular de forma racional, ou seja, analisando todas as suas funcionalidades e comparando-o com a concorrência para comprar de nossas marcas prediletas e, assim, consumimos na realidade a marca e não o produto em si. 


\section{Referencial Teórico}

\subsection{Marca}

Segundo a American Marketing Association (apud KELLER e MACHADO, 2006, p.2), "marca é um nome, termo, sinal, símbolo, desenho ou combinação desses elementos que deve identificar os bens ou serviços de um fornecedor ou grupo de fornecedores e diferenciálos dos da concorrência". Ademais, segundo Kotler e Keller (2012), todas as empresas se esforçam com o intuito de estabelecer uma imagem de marca a mais sólida, favorável e exclusiva possível. Isso demonstra o quão essencial é investir na construção de uma marca forte para que a mesma se diferencie no mercado em que está inserida e consiga se estabelecer nele.

Além disso, a palavra brand (marca em inglês) deriva do nórdico antigo brandr, que significa "queimar", isto porque as marcas a fogo eram, e de certa maneira ainda são, usadas pelos proprietários de gado como forma de marcar e identificar seus animais (KELLER e MACHADO, 2006). Portanto, fica nítido que o principal objetivo de uma marca é se diferenciar das demais.

Uma marca pode ser definida também, como sendo um produto, porém um produto que acrescenta outras dimensões que o diferenciam de outros produtos desenvolvidos para satisfazer a mesma necessidade (KELLER e MACHADO, 2006). Cabe também mencionar que, segundo Keller e Machado (2006), uma marca é um ativo intangível extremamente valioso que precisa ser tratado com cautela. $E$ isso é de suma importância para que ela consiga se tornar uma marca de sucesso. Para Kotler e Keller (2012), a marca é algo que penetra na mente dos consumidores e, por isso, a mesma precisa dar bastante foco em ser percebida pelo seu público-alvo de modo positivo.

Já Kapferer (2004) entende que marca é um sistema vivo, que é composto por três elementos: um multissinal (como identidade gráfica, nome e símbolo), associado a produtos e serviços, que por sua vez, são associados a alguma promessa de qualidade; segurança e pertinência a um universo. Com isso, nota-se como esse é um conceito amplo e que possui um conjunto de significados.

Na concepção de Solomon (2011), quando nos apaixonamos por uma marca, ela tem grandes chances de se tornar nossa favorita pelo resto de nossas vidas. Isso demonstra como 
elas impactam e influenciam em nossas decisões, pois buscamos sempre escolher aquelas que são nossas prediletas.

Já na visão de Aaker (1998), uma marca é um nome diferenciado e/ou símbolo (tal como um logotipo, marca registrada, ou desenho de embalagem) com o propósito de identificar os bens ou serviços de um vendedor ou de um grupo de vendedores e a diferenciar esses bens e serviços daqueles dos concorrentes e assim, uma marca indica ao consumidor a origem do produto e protege, tanto o consumidor quanto o fabricante, dos concorrentes que oferecem produtos que pareçam iguais.

Por fim, para Keller (2001), criar uma marca forte é o objetivo de muitas organizações e para isso, é necessário seguir quatro passos para que se construa uma marca consolidada: assegurar que os clientes se identifiquem com a marca e associem a mesma com uma categoria específica de produto, serviço ou necessidade do cliente; estabilizar o significado da marca na mente dos clientes, de forma estratégica, visando a que eles tenham uma série de associações com a marca (tangíveis e intangíveis); obter as respostas necessárias, por parte dos consumidores, para criar identidade e significado de marca; e, finalmente, converter a resposta de marca buscando criar um relacionamento duradouro e de lealdade com o cliente. Esses passos formam a chamada pirâmide de construção de brand equity (figura 2).

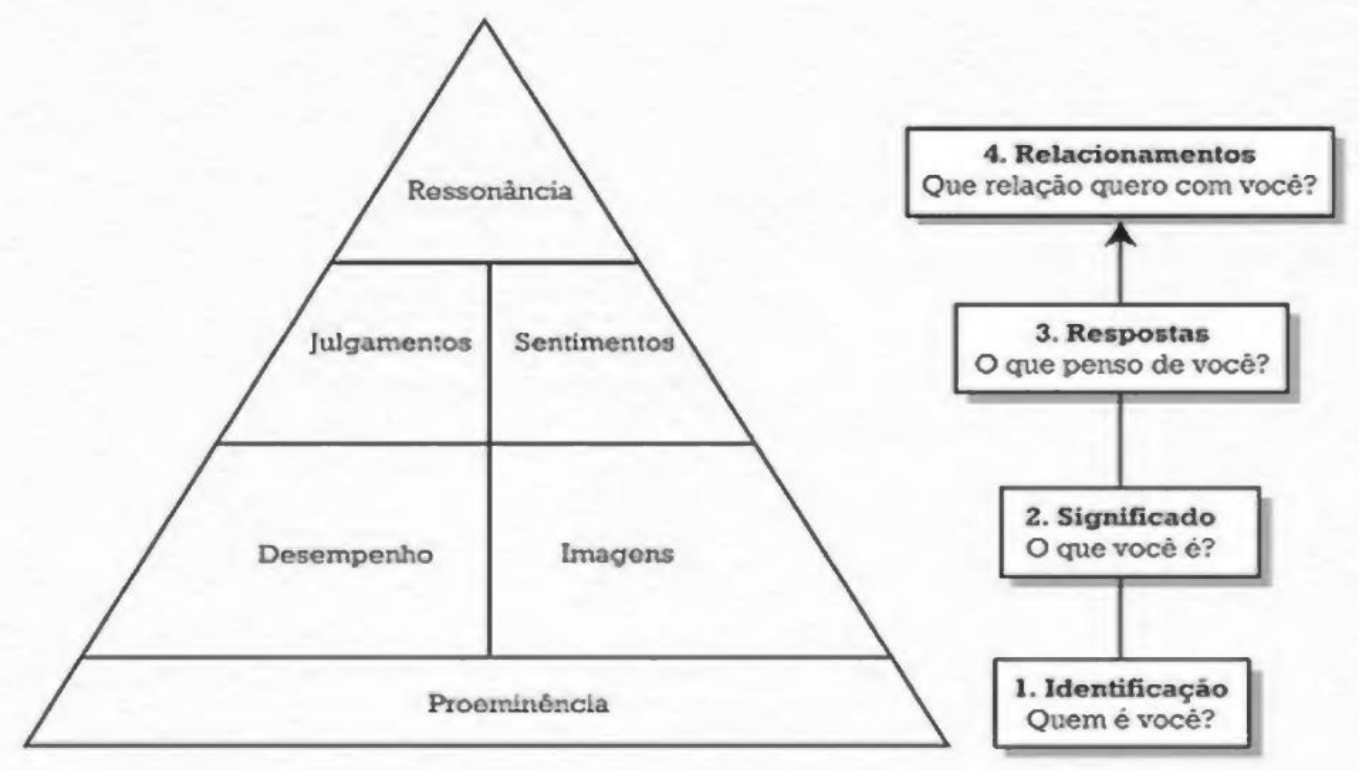

Figura 2: Pirâmide de Construção de Brand Equity

Fonte: Keller e Machado (2006)

No mercado de smartphones, as marcas fortes possuem extrema relevância e um exemplo disso é a Apple, que é uma marca consolidada e que possui uma enorme base de clientes fiéis devido ao seu poder de sua marca. Segundo uma pesquisa realizada, no Brasil, 
pela MeSeems (2014), a Apple foi a marca preferida de $36 \%$ dos entrevistados, obtendo a maior porcentagem entre as marcas no setor de smartphone desse estudo. Isso mostra o quanto as pessoas se identificam com essa marca. Além disso, segundo os dados da pesquisa da MeSeems (2014), 48\% dos entrevistados afirmaram que a reputação da marca influencia em sua decisão de compra. Ademais, segundo os dados do reporte anual das marcas mais valiosas do mundo, realizado pela Brand Finance (2019), a Apple é a segunda marca mais valiosa do mundo, com um valor de mercado de aproximadamente 153 bilhões de dólares e um crescimento de 5\%, se comparado ao seu valor no ano de 2018.

\subsection{Brand Equity}

Segundo o Marketing Science Institute (apud KELLER e MACHADO, 2006, p.30), brand equity pode ser definido como:

Um conjunto de associações e comportamentos da parte de clientes, membros do canal e empresa controladora da marca que permite à marca ganhar maior volume ou maiores margens do que conseguiria sem o nome da marca e que lhe dá uma vantagem forte, sustentável e diferenciada sobre os concorrentes.

Isso mostra que esse é um conceito que está relacionado diretamente ao valor que uma marca possui perante seus consumidores e como isso pode gerar retornos financeiros e não financeiros (como reconhecimento) para ela.

Por outro lado, o brand equity pode também ser definido como o valor agregado atribuído a bens e serviços. Tal valor pode ser refletido na maneira como os consumidores pensam, sentem e agem em relação à marca, bem como nos preços, na participação de mercado e na lucratividade gerada pela marca (KOTLER e KELLER, 2012).

Já para Aaker (1998), o brand equity é um conjunto, tanto de ativos como de passivos, ligados a uma marca, seu nome e seu símbolo, que se somam ou subtraem do valor proporcionado por um produto ou serviço para uma empresa e/ou para seus consumidores. Por isso, é necessário analisar todos os ativos e passivos ligados a uma marca, para que se torne possível a sua construção de brand equity e, por conseguinte, a criação de valor.

Vale também ressaltar que o valor de uma marca está atrelado a um conjunto de atributos e potenciais fraquezas relacionados ao nome dela e para medir esse valor utilizamse cinco categorias principais, que são: percepção de marca; lealdade de marca; qualidade 
percebida; outros ativos (como patentes, trademarks e relações com os canais de distribuição); e associação de marca (AAKER, 1996).

O valor da marca está atrelado às percepções que os consumidores possuem do valor que os produtos e serviços de uma marca proporcionam (KOTLER e ARMSTRONG, 2003). E quanto mais positiva é essa percepção, mais valor os consumidores dão para aquela marca.

Para Kohli e Leuthesser (2001), brand equity está ligado ao diferencial que o conhecimento sobre uma marca, por parte do cliente, influencia em sua resposta. Ademais, é essencial comentar que existem três elementos que norteiam essa definição, que são: a diferenciação, que é o pressuposto básico para que uma marca se diferencie de outra e dessa forma consiga se destacar no mercado em que se está inserida; o conhecimento da marca, visto que os consumidores precisam conhecer a marca em questão e como sua diferenciação pode ser significativa para eles; e, por fim, o último elemento relevante dessa definição é a resposta dos clientes, pois eles precisam responder favoravelmente à diferenciação que a marca possui e com isso gerar um desejo, por parte deles, em consumir os produtos daquela marca e se fidelizar a ela, ou seja, eles estariam dispostos a pagar pelo que ela oferece (KOHLI E LEUTHESSER, 2001).

Para Serra e Gonzalez (1998), é de suma importância que a marca possua valor entre os consumidores, já que quando os clientes são fiéis a alguma marca, eles naturalmente são uma barreira de entrada para novas empresas, uma vez que estas novas marcas terão dificuldades em chamar atenção desses clientes que já possuem fidelidade a outra marca.

Finalmente, segundo Kotler e Keller (2012), o valor que uma marca transmite pode ser definido como sendo o conjunto de benefícios que ela dispõe visando satisfazer às necessidades dos consumidores. Ademais, o consumidor escolhe, entre diversas ofertas diferentes, aquela que the parece proporcionar o maior valor possível (KOTLER e KELLER, 2012). Com isso, as marcas precisam sempre visar à entrega de uma alta proposta de valor e, assim, gerar uma percepção positiva nos seus consumidores para que ela se torne preferência entre eles.

\subsubsection{Branding}

Branding é um termo que pode ser definido como um conjunto de atividades que tem como objetivo melhorar a gestão das marcas de uma organização como diferencial competitivo (KELLER e MACHADO, 2006). Ademais, segundo Keller e Machado (2006), tal 
conceito fundamentalmente tem com significado dotar produtos e serviços de brand equity, ou seja, de valor de marca.

Para Kotler e Keller (2012), branding está atrelado ao fato de dotar bens e serviços com o poder de uma marca e está diretamente ligado em criar diferenças. Além disso, esse conceito corresponde a criar estruturas mentais e auxiliar o consumidor a organizar seu conhecimento sobre os produtos buscando tornar sua tomada de decisão mais palpável e assim, gerar valor à empresa.

Em suma, esse conceito está diretamente ligado ao fato de uma marca construir uma percepção, para seus consumidores, positiva e conseguir, através disso, um diferencial competitivo no mercado em que a mesma está inserida.

Um exemplo disso, no mercado de smartphones, seria a Samsung, que ao longo dos anos conseguiu construir uma imagem de marca muito consolidada e, com isso, segundo um estudo realizado pelo Valor Data (2018), conseguiu crescer, em 2018, mais de 15\% no Brasil e atingir um faturamento com vendas no valor de $\mathrm{R} \$ 23,2$ bilhões, o que mostra que, mesmo em um período de recessão econômica no país, a empresa não teve seu resultado prejudicado e um dos motivos que explicam isso é justamente o fato de seus consumidores terem uma percepção favorável da marca.

\subsubsection{Escala Multidimensional de Brand Equity de Yoo e Donthu (2001)}

A escala multidimensional de brand equity (MBE) foi desenvolvida por Yoo e Donthu (2001), levando em consideração estudos prévios sobre o tema, como as teorias de brand equity dos autores Aaker (1998) e Keller (1993) e também a partir de um estudo anteriormente desenvolvido por Yoo, Donthu e Lee (2000). Com isso, chegou-se a um modelo com quinze itens para medir quatro conceitos que compõem o brand equity (lealdade de marca, lembrança de marca, qualidade percebida e associações de marca). Todavia, no momento de validação desse modelo, os autores perceberam que os fatores de lembrança e associações à marca não se manifestaram de forma distinta, diferentemente do modelo de Aaker (1998), ou seja, esses dois fatores manifestaram-se como sendo apenas uma dimensão. Portanto, Yoo e Donthu (2001) criaram seu próprio modelo levando em consideração somente três dimensões (conforme a figura 3 ) e com isso, incluíram em sua escala dez itens. 


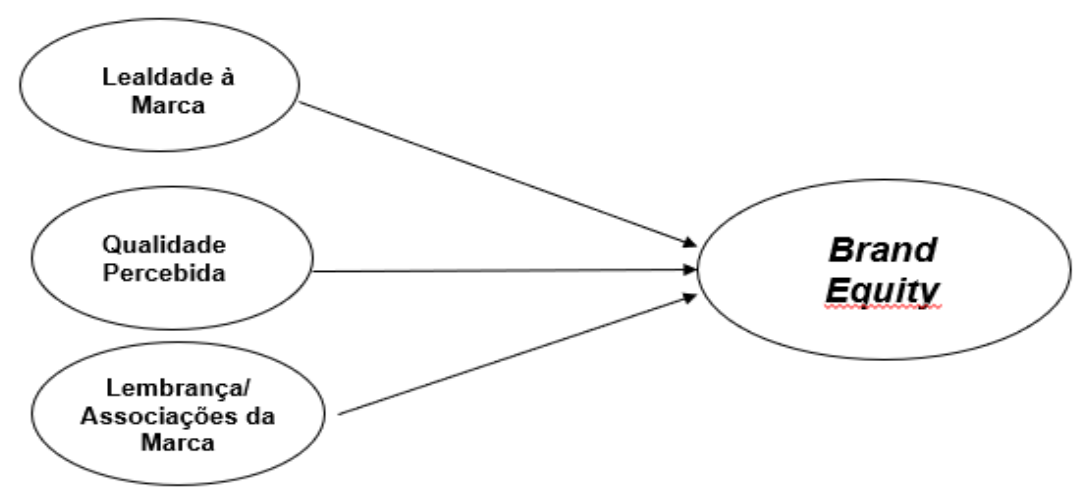

Figura 3: Modelo de Yoo e Donthu

Fonte: Yoo e Donthu (2001)

Essa escala ajuda a compreender quais são as características mais relevantes das marcas para os consumidores e também entender melhor a tomada de decisão deles diante das dimensões de brand equity.

Uma adaptação da escala multidimensional de brand equity (MBE), de Yoo e Donthu (2001), será utilizada na aplicação do questionário deste trabalho, no próximo capítulo (metodologia), e será explicada com maiores detalhes posteriormente e anexada ao final do trabalho.

\subsection{Comportamento do Consumidor}

Para Engel, Blackwell e Miniard (2000), o comportamento do consumidor pode ser definido como sendo as atividades que estão diretamente envolvidas em obter, consumir e dispor de produtos e serviços, englobando os processos decisórios que antecedem e sucedem estas ações.

Tal conceito também pode ser definido como sendo o estudo dos processos envolvidos no momento em que indivíduos ou grupos selecionam, compram, usam ou descartam produtos, serviços, ideias ou experiências visando satisfazer tanto necessidades quanto desejos (SOLOMON, 2011). E isso mostra que nossa principal motivação em comprar algo é para atender alguma necessidade ou realizar algum desejo.

Segundo Howard e Sheth (apud BENNETT, 1980, p.17), "o estímulo mais importante a afetar o comportamento do consumidor são as pistas de informação sobre um conjunto de características do produto ou marca (qualidade, preço, caracterização, serviço e disponibilidade", o que demonstra a preocupação que as marcas precisam ter com esses 
aspectos, uma vez que eles afetam diretamente a maneira como os consumidores se comportam.

De acordo com Schiffman e Kanuk (2000), o estudo do comportamento do consumidor baseia-se no estudo que visa descobrir como os indivíduos tomam decisões de gastar seus recursos financeiros e não financeiros (como tempo e esforço) disponíveis em itens que são relacionados ao consumo. Com isso, pode-se concluir que esse é um processo que engloba diversas variáveis que visam entender melhor a mente do consumidor. Ademais, o termo "consumidor" é comumente utilizado para delinear dois tipos distintos de entidades consumidoras: uma é o consumidor pessoal, que compra bens e serviços para uso próprio ou para uso de seus amigos, familiares ou até mesmo pessoas próprias, ou seja, são comprados para os consumidores finais daquele produto/serviço ; a outra entidade é o consumidor organizacional, que engloba organizações com e sem fins lucrativos, diversos órgãos do governo (como municipal e estadual) e instituições civis (como escolas e hospitais), em que todos nessa categoria necessitam comprar produtos, equipamentos e serviços para funcionarem normalmente (SHIFFMAN e KANUK, 2000).

Já na visão de Churchill e Peter (2012), esse conceito engloba os pensamentos, sentimentos e ações dos consumidores e as influências que os afetam e geram mudanças. Dentre as influências existentes, que afetam o comportamento dos consumidores, podemos citar as: influências sociais, que se referem aos vários grupos que cada pessoa é de alguma forma influenciada (cultura, subculturas, classe social, grupos de referência e família); influências de marketing, que estão ligadas a cada elemento do composto de marketing (produto, preço, praça e promoção); e, influências situacionais, que possuem ligação direta com características da situação pela qual o indivíduo está exposto no momento da compra, como o ambiente físico do local em que ele está comprando, o ambiente social (inclui as outras pessoas presentes no ambiente e o papel que parecem desempenhar e a forma que interagem entre si), o tempo (a influência da hora sobre o comportamento de compra do consumidor), a tarefa (razões gerais ou específicas para coletar informações, sair às compras ou até mesmo comprar) e as chamadas condições momentâneas, como o humor e as condições do comprador naquele momento específico (CHURCHILL e PETER, 2012). Portanto, podemos concluir que existem diversas variáveis que podem afetar nosso comportamento como compradores e por conseguinte, nossa tomada de decisão de compra. 


\subsubsection{Decisão de Compra do Consumidor}

As pessoas possuem uma tendência a comprar produtos e serviços de uma marca conhecida devido ao sentimento de conforto que lhes é familiar e, com isso, tal marca leva vantagem perante uma marca desconhecida (AAKER, 1998). Com isso, torna-se evidente a vantagem de ser uma marca conhecida no mercado em que se está inserido.

Outro fator que também influencia a decisão de compra do consumidor é a qualidade percebida, ou seja, a percepção que os consumidores possuem da marca (AAKER, 1998). Portanto, quanto maior essa qualidade percebida é, maiores as chances dos indivíduos a consumirem.

Segundo Kotler e Keller (2012), é importante destacar que o comportamento de compra do consumidor é influenciado por: fatores culturais, sociais e pessoais. E dentre estes, o que possui maior e mais profunda influência são os fatores culturais, o que demonstra a grande importância da cultura para esse processo, uma vez que somos moldados para termos desejos e comportamentos condizentes aos aspectos culturais do local onde vivemos.

No momento de decisão de compra, o consumidor cria preferências entre as marcas e tende a escolher aquelas que são suas favoritas (KOTLER e KELLER, 2012). Devido a isso, é de extrema importância que as marcas sempre busquem estar na preferência de seus consumidores, para que, assim, consigam um alto reconhecimento no mercado e com isso gerar um maior volume de vendas.

Um fator que é tão importante quanto a intenção de compra do consumidor é a sua atitude em relação ao produto ou marca (ENGEL, BLACKWELL e MINIARD, 2000). Contudo, a atitude dele é afetada por diversas outras complexas variáveis, o que torna a escolha dele um processo ainda mais difícil.

Para Solomon (2011), o consumidor realiza uma compra para resolver algum problema e, para tomar uma decisão, ele passa por cinco passos, que são: reconhecimento do problema; busca de informações; avaliação de alternativas; escolha do produto e; por fim, chega-se aos resultados. Ademais, a decisão que os consumidores tomam para solucionar tal problema tende a ser repetir nas próximas vezes que eles passarem pela mesma situação (SOLOMON, 2011). Dessa forma, é essencial que as marcas se esforcem ao máximo para conseguirem encarar o desafio que é estar nas alternativas das pessoas e gerar fidelização por parte delas, visto que a concorrência nos distintos mercados, especialmente hoje em dia, é enorme. 
Por fim, de acordo com Churchill e Peter (2012), o processo de compra do consumidor é impactado por três tipos de tomada de decisão: rotineira, que costuma ocorrer na compra de produtos conhecidos, baratos e simples, já que os consumidores não acreditam que esse tipo de compra seja importante e por isso não se envolvem demasiadamente com ela (pouca atividade de pesquisa e compra); limitada, na qual os compradores estão dispostos a gastar parte de seu tempo procurando valor nos produtos procurados, entretanto eles manterão baixos seu custo de tempo e esforço (nível moderado de atividade de pesquisa e compra) e; extensiva, que normalmente é utilizada no caso de produtos mais complexos, pouco conhecidos, caros ou então muito significativos para os consumidores (considerável atividade de pesquisa e compra).

\subsection{Percepção}

A percepção pode ser compreendida como o processo pelo qual um indivíduo seleciona, organiza e interpreta as informações que ele recebe, visando criar uma imagem significativa do mundo (KOTLER e KELLER, 2012). Ademais, tal fenômeno depende de estímulos físicos e da relação que esses estímulos possuem com o ambiente, além das condições internas de cada um (KOTLER e KELLER, 2012). Portanto, cada indivíduo pode ter uma percepção diferente sobre o mesmo assunto.

Para Bennett (1980), a percepção é um processo em que o indivíduo recebe estímulos e os atribui um sentido se baseando em memórias de aprendizados, expectativas, fantasias, crenças, atitudes e sua personalidade. Em nosso dia a dia, possuímos diversas percepções que nos permitem formar uma opinião sobre algo.

Esse conceito também pode ser definido como sendo o processo pelo qual os indivíduos selecionam, organizam e interpretam as sensações que sentem (SOLOMON, 2011). Com isso, buscamos sempre dar significado para as coisas que sentimos e isso gera a percepção sobre algo.

Segundo Kotler e Keller (2012), nós agimos de acordo com a percepção que temos de alguma situação. Portanto, nossas ações possuem ligação com a forma pela qual percebemos o que está acontecendo ao nosso redor.

Na visão de Schiffman e Kanuk (2001), a percepção está diretamente ligada à maneira como os indivíduos enxergam o mundo à sua volta, ou seja, diferentes sujeitos podem enxergar a mesma coisa de diferentes perspectivas (por exemplo: uma pessoa acha camisa de cor azul formosa enquanto o outro indivíduo pode achar camisas azuis deselegantes). Com 
isso, pode-se afirmar que as pessoas, no processo receptivo, reconhecem, selecionam, organizam e interpretam estímulos aparentemente iguais de formas diferentes e esse é um processo individual baseado em diversas variáveis, como as necessidades, valores e expectativas de cada um. (SCHIFFMAN e KANUK, 2001).

Contudo, pode-se concluir que a percepção que os indivíduos possuem perante as marcas é determinante para que eles sejam clientes ou não delas, dependendo se tal percepção é positiva ou negativa. Em adição a isso, segundo Schiffman e Kanuk (2001), entende-se motivação como sendo a força motriz interna das pessoas que as leva à ação, ou seja, para que os consumidores possuam motivação para comprar um produto/serviço, é de suma importância que a marca seja percebida favoravelmente, pelos compradores, no mercado em que está inserida, caso contrário, o mesmo não estará motivado a comprar e nem disposto a se fidelizar a ela. 


\section{Metodologia}

\subsection{Tipo de Pesquisa}

O tipo de pesquisa utilizado no presente trabalho foi a descritiva. Esse tipo de pesquisa, segundo Vergara (2000), expõe características de uma determinada população ou fenômeno, além de estabelecer correlações entre diferentes variáveis e também definir sua natureza. $O$ intuito da pesquisa realizada foi descobrir o grau de impacto que a marca possui na decisão de compra dos consumidores no setor de smartphones.

\subsection{Universo e Amostra}

O universo do estudo são os consumidores de smartphones das quatro principais marcas de smartphone no Brasil: Samsung, Motorola, Apple e LG, que residam no estado do Rio de Janeiro e estejam na faixa etária de 18 a 31 anos. Vale ressaltar que o método de amostragem utilizado foi o não probabilístico, abordagem por conveniência, visando alcançar o maior número de indivíduos com facilidade. Em relação ao universo, destaca-se que a população da cidade do Rio de Janeiro, é de 6,72 milhões de habitantes (IBGE, 2019) porém o universo real desta pesquisa é menor que esse número, visto que não são todos da cidade que possuem algum smartphone.

A quantidade de respostas coletadas foi considerada satisfatória, levando em consideração a natureza do trabalho. Todavia, se a amostra fosse probabilística, poderia ser considerado razoável uma margem de erro menor que 10\%. Dessa forma, considerando que a amostra foi de 190 respondentes, sendo 135 válidos (por se enquadrarem nas delimitações desse trabalho), isso resultaria em uma margem de erro de 8,43\% ${ }^{1}$. Dos 135 respondentes

\footnotetext{
${ }^{1}$ A margem de erro, para esse caso, foi calculada através do site Raosoft, utilizando a fórmula: $E=\sqrt{\frac{(N-n) x}{n(N-1)}}$, onde $n=\frac{N x}{\left((N-1) E^{2}+x\right)}$ e $x=Z\left(\frac{c}{100}\right)^{2} r(100-r)$, sendo $n$ o tamanho da amostra válida, $N$ o tamanho da população, $r$ corresponde à fração de respostas de interesse e por fim, $Z\left(\frac{c}{100}\right)$ é o valor crítico para o nível de confiança $c$. Vale ressaltar que não foi utilizado o tamanho real da população, portanto, a margem de erro real é ligeiramente menor do que a calculada mas isso tem um impacto numérico muito baixo no cálculo do valor da margem de erro.
} 
considerados válidos, 60 (44,44\%) utilizam algum smartphone da Apple, 45 (33,33\%) da Samsung, 25 (18,52\%) da Motorola e 5 da LG (3,70\%).

Além disso, foi utilizado também o método Bola de Neve, pois foi solicitado que os respondentes do questionário repassassem o mesmo para mais pessoas, visando ampliar o alcance da pesquisa.

\subsection{Coleta de Dados}

Foi realizado um questionário utilizando o Qualtrics (uma plataforma online de elaboração e realização de questionários, pesquisa e afins). O questionário foi desenvolvido levando em consideração uma adaptação do modelo de Yoo e Donthu², visando adequar tal escala ao mercado de smartphone. O questionário foi distribuído via redes sociais (principalmente pelas plataformas Instagram, Facebook e WhatsApp).

No questionário ${ }^{3}$ realizado, foram feitas 15 perguntas fechadas (no formato de múltipla escolha), sendo 10 questões de análise da opinião dos respondentes (com o objetivo de descobrir, dentre outros aspectos, os dados sobre uso e preferência de marcas de smartphones por parte dos consumidores e, com isso, mapear as opiniões deles sobre diferentes aspectos) e 5 questões relacionadas ao perfil do respondente (dados pessoais), visando traçar o perfil das pessoas que responderam ao questionário.

Ademais, o questionário utilizou, em grande parte das perguntas, a escala de Likert ${ }^{4}$, buscando medir o nível de concordância dos respondentes em relação às perguntas elaboradas. Finalmente, para a realização da coleta de dados, os dados gerados foram exportados para uma planilha na aplicação Microsoft Excel para tornar a interpretação mais fácil. Gráficos e tabelas também foram utilizados para a ilustração dos resultados alcançados.

\footnotetext{
2 Tal escala está no Anexo 2 do trabalho.

${ }^{3} \mathrm{O}$ questionário está disponível através do link: https://pucrio.co1.qualtrics.com/jfe/form/SV_cABkkibuLVeHfmt. Ademais, se encontra no Anexo 1 do trabalho.

${ }^{4}$ A escala de Likert, desenvolvida pelo psicólogo norte-americano Rensis Likert (em 1932), é um sistema de classificação que é usado em questionários e foi elaborado para medir as atitudes, opiniões ou percepções dos indivíduos.
} 


\subsection{Tratamento dos Dados}

Os dados coletados foram tratados utilizando a abordagem quantitativa, que procura fornecer informações numéricas. O método foi utilizado com o intuito de obter valores numéricos para a percepção do consumidor sobre o tema em questão.

Além disso, o tratamento dos dados foi feito usando a estatística descritiva, em que a média aritmética foi a principal medida usada.

Por fim, para os cálculos, foram realizadas tabelas dinâmicas (se baseando na base de dados coletada) na ferramenta Microsoft Excel e, dessa forma, foi possível calcular as médias, realizar cruzamentos de dados filtrando por diferentes categorias que foram definidas através das respostas coletadas na seção "Perfil do respondente" do questionário realizado e também foram gerados gráficos e tabelas com os dados encontrados.

Esse tratamento de dados permitiu que a análise apresentada a seguir (no capítulo 4) fosse estruturada.

\subsection{Limitações do Método}

O método adotado não consegue medir se o respondente realizou o questionário de forma parcial com a finalidade de privilegiar sua própria marca de smartphone. Todavia, também não é possível mensurar se o respondente guarda alguma frustração em relação à marca de seu smartphone e se isso influenciou de alguma forma suas respostas. 


\section{Análise de Resultados}

\subsection{Perfil dos Respondentes}

No questionário aplicado, conforme citado anteriormente, foram realizadas cinco perguntas em relação ao perfil dos respondentes, que buscavam verificar qual a marca do smartphone do respondente, a idade, o sexo, o grau de escolaridade e a renda familiar deles. $O$ intuito dessa bateria de perguntas foi traçar o perfil dos respondentes e realizar posteriormente análises cruzadas. Vale ressaltar que essas perguntas foram realizadas no final do questionário (com exceção da pergunta sobre qual a marca do smartphone atual do respondente, que foi a primeira pergunta da pesquisa) porém todas elas serão analisadas a seguir.

O Gráfico 1 apresenta a quantidade de usuários de smartphones por marca. Nota-se que $44,44 \%$ possuem smartphone da Apple, 33,33\% da Samsung, 18,52\% da Motorola e por fim, 3,70\% da LG. Com isso, fica evidente que a maioria das pessoas são clientes da Apple e da Samsung, que juntos possuem $77,78 \%$ das respostas válidas.

Gráfico 1: Marcas do Smartphones dos Respondentes

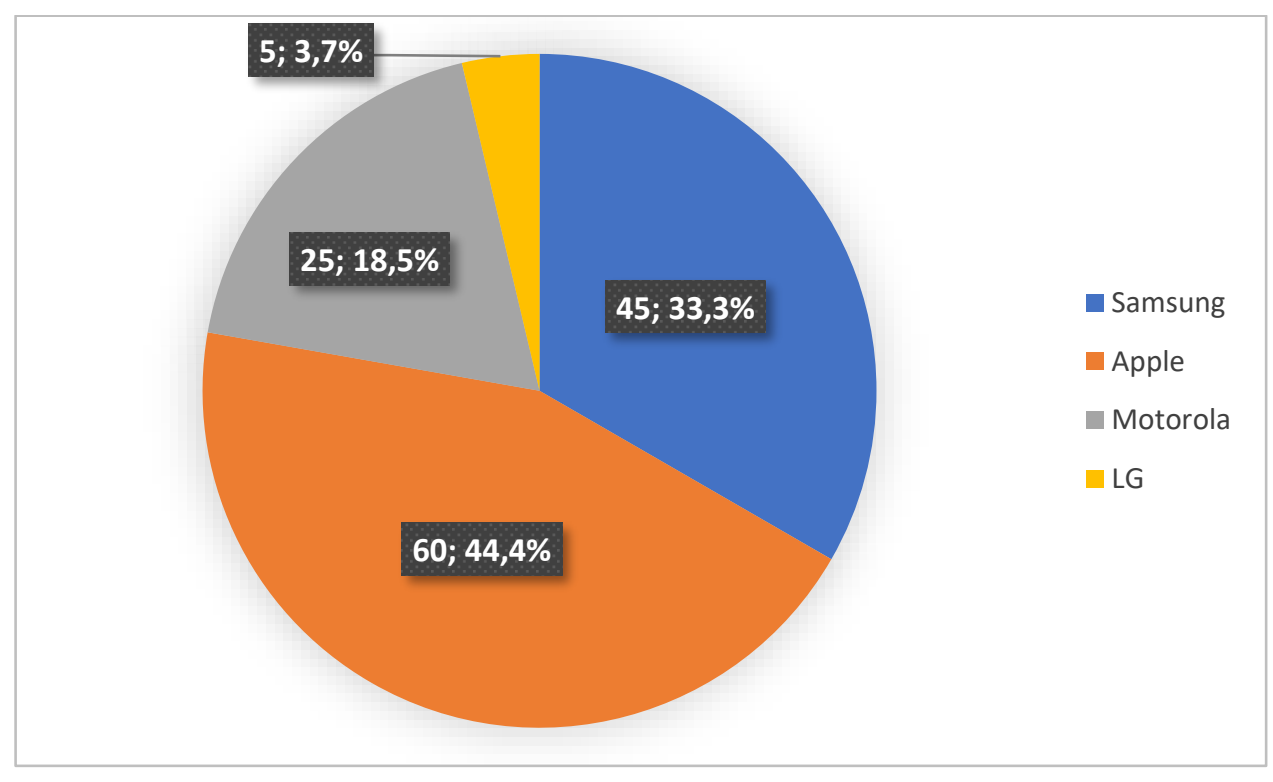

Fonte: Pesquisa de Campo (2019)

Já o Gráfico 2 refere-se à faixa etária dos respondentes considerados válidos e podese observar que a maioria deles possui entre 18 e 24 anos (72,59\%) enquanto os outros 
$27,41 \%$ estão inseridos na faixa etária de 25 a 31 anos, demonstrando assim que os respondentes válidos são considerados parte do público jovem.

Gráfico 2: Faixa Etária dos Respondentes

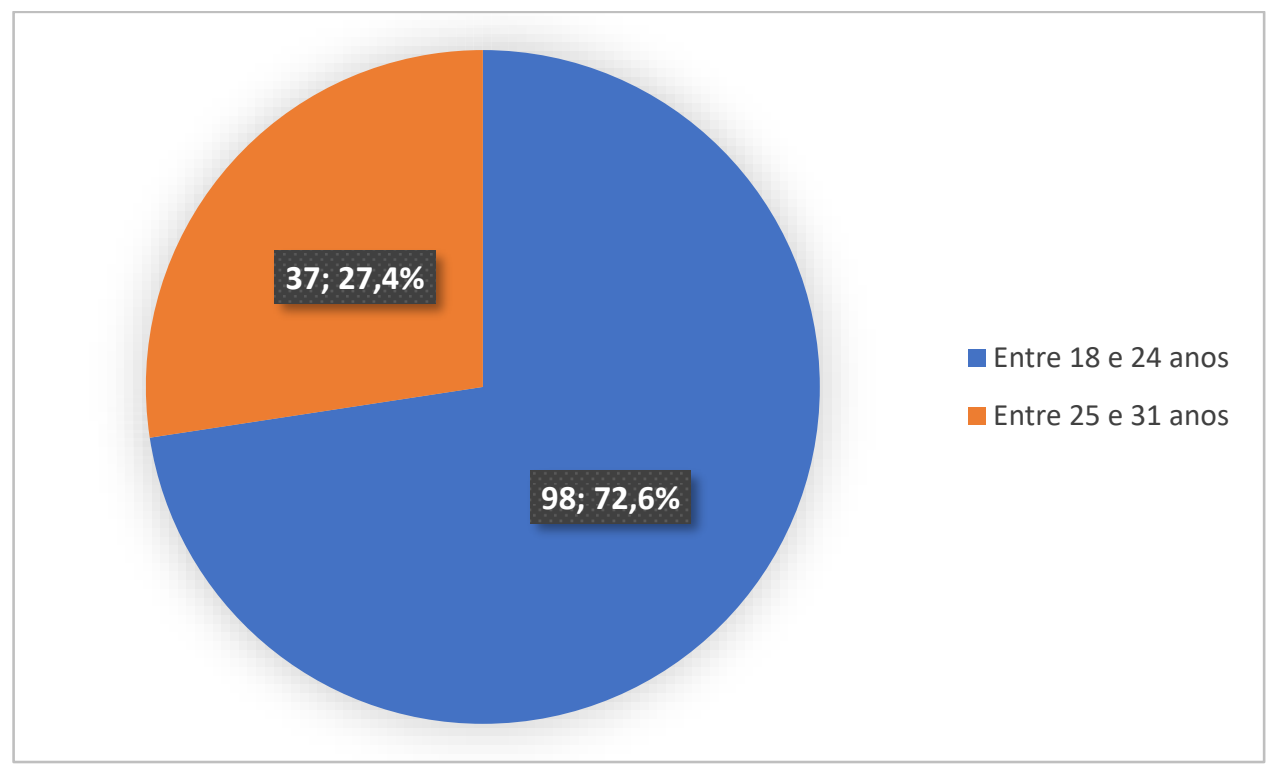

Fonte: Pesquisa de Campo (2019)

No Gráfico 3, observa-se que a amostra da pesquisa não oscilou muito em relação ao sexo dos respondentes e a mesma ficou bastante equilibrada em relação a esse quesito: $51,11 \%$ foram do sexo feminino e $48,89 \%$ do sexo masculino.

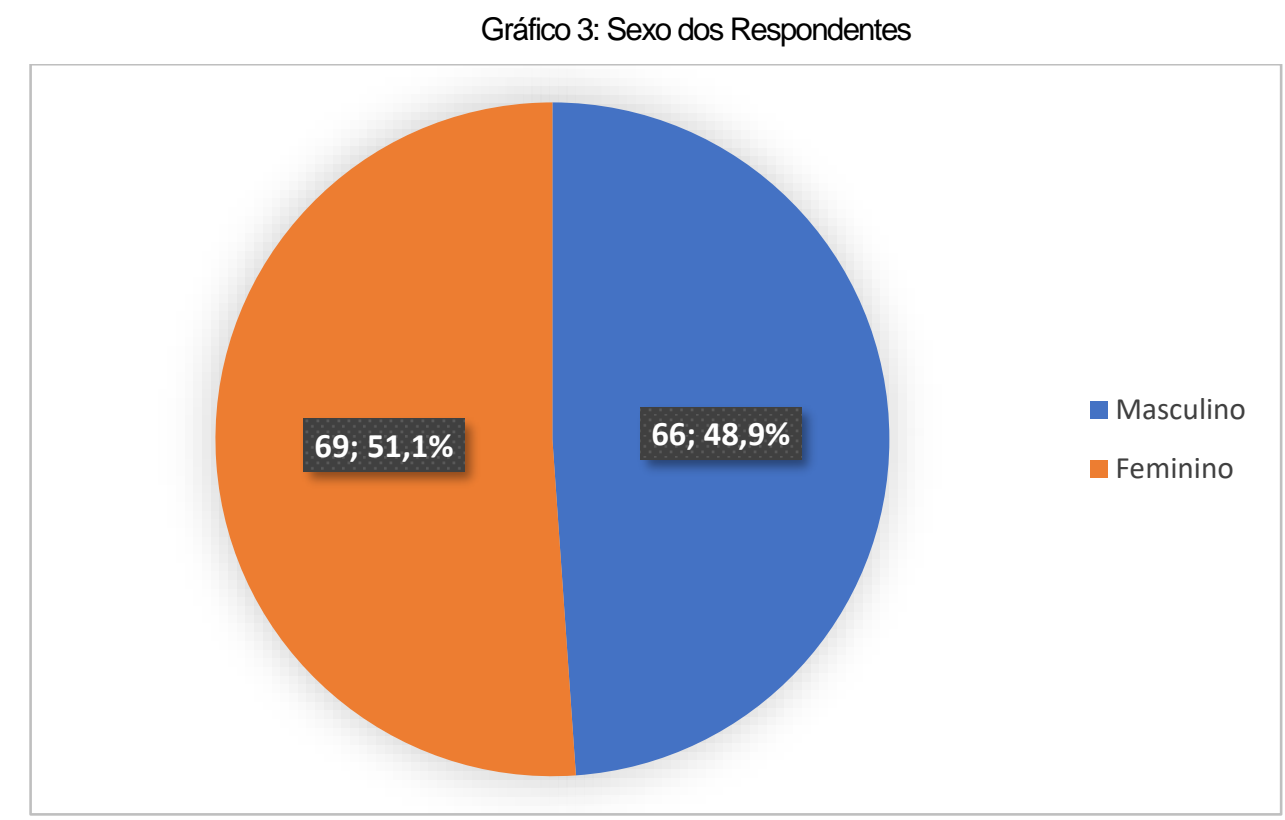

Fonte: Pesquisa de Campo (2019)

Em relação ao nível de escolaridade, conforme mostrado no Gráfico 4, fica em evidência que a maior parte dos respondentes (66,67\%) está na faixa de ensino superior 
incompleto/cursando, ou seja, são universitários. Ademais, a segunda faixa com a maior concentração de respondentes é a de ensino superior completo (15,56\%). Por fim, as demais faixas de ensino, juntas, somam $17,78 \%$ das respostas válidas.

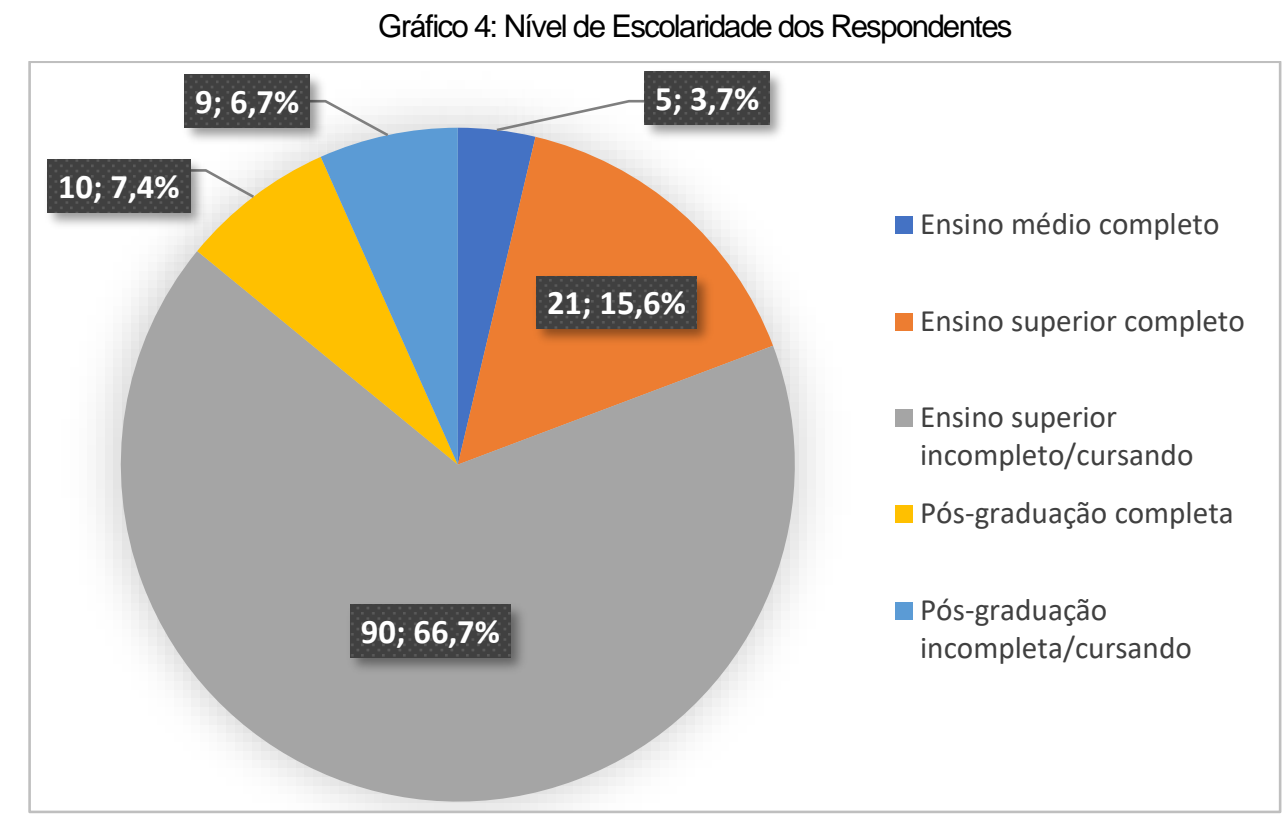

Fonte: Pesquisa de Campo (2019)

Finalmente, a última pergunta sobre perfil foi a de renda familiar, que pode ser visualizada no Gráfico 5. Com esse, percebe-se que a classe $B$ (renda mensal entre $R \$$ $9.980,01$ e $\mathrm{R} \$ 19.960,00$ ) possui a maior representatividade entre os respondentes, com o total de $31,85 \%$, seguido da classe $A$ (renda mensal acima de $R \$ 19.960,01$ ) com $22,22 \%$ e da classe $C$ (renda mensal entre $R \$ 3992,01$ e $R \$ 9.980,00$ ). Além disso, as classes $D$ e $E$ (representadas pela renda mensal até $\mathrm{R} \$ 3.992,00$ ), juntas, somam $25,93 \%{ }^{5}$.

É válido também destacar que os respondentes, em termos de opinião, não demonstraram uma grande diferenciação relacionada a faixa etária, sexo, nível de escolaridade e renda familiar. Dessa forma, a única pergunta de perfil que diferencia as opiniões, de forma significativa, é a marca de smartphone que os respondentes utilizam.

\footnotetext{
${ }^{5}$ As classes sociais foram utilizadas com base em estudos do IBGE, em uma matéria escrita pela British Broadcasting Corporation (BBC), disponibilizado no portal do G1, do Globo, em 2019. Ademais, o salário mínimo foi contabilizado como sendo $\mathrm{R} \$ 998,00$, valor disponibilizado no site do Governo Federal com base no decreto assinado pelo presidente do país em relação ao salário mínimo vigente no ano de 2019.
} 
Gráfico 5: Renda Familiar dos Respondentes

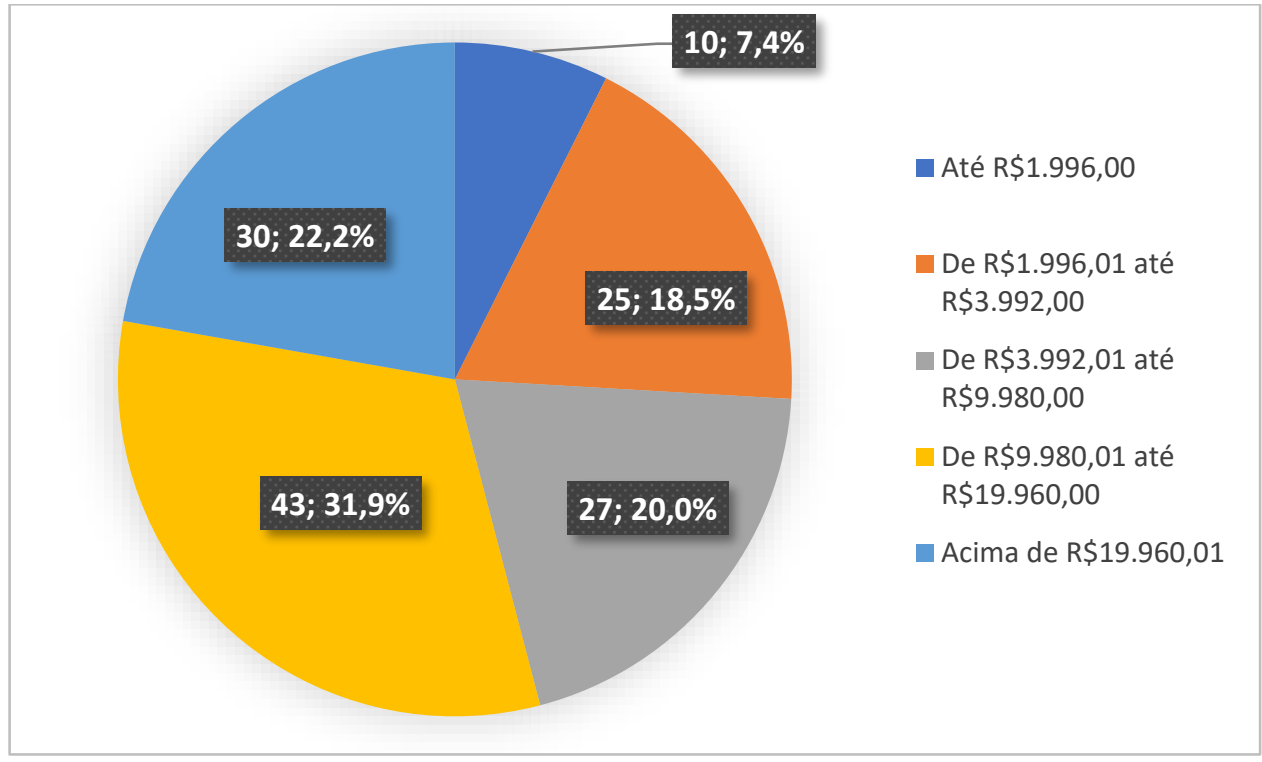

Fonte: Pesquisa de Campo (2019)

\subsection{Critérios Importantes na Decisão de Compra}

Visando obter os critérios mais importantes na decisão de compra de um smartphone, na ótica dos consumidores, foi utilizada a pergunta: "Quais são os critérios que você considera mais importantes para decidir qual smartphone comprar?".

Com isso, levando em consideração os 135 respondentes considerados válidos (que totalizaram 454 votos nessa pergunta, pelo fato de que cada respondente conseguia votar em quantos critérios quisesse), pode-se observar, conforme a Tabela 1, que os quatro critérios mais relevantes, que juntos somam 52,20\% dos votos, são: preço, com 15,64\%; qualidade da câmera, com 14,98\%; sistema operacional, com 11,67\%; e, marca, com 9,91\%.

Um dado interessante de se destacar é que dos 45 votos no critério marca, $62,22 \%$ foram de usuários de smartphones da Apple, o que demonstra como essa marca possui clientes que reconhecem o valor dela e dão importância a esse fator.

Ademais, podemos observar também que, nesse setor, há uma tendência aos consumidores serem sensíveis ao preço, visto que esse foi o critério mais votado, com 15,64\% dos votos. Dessa forma, esse é um desafio que as marcas do setor precisam enfrentar. Todavia, desses 71 votos em preço, apenas 26,83\% foram de usuários da Apple, mostrando mais uma vez o fato deles considerarem a marca como um fator importante, não sendo tão sensíveis ao preço como os usuários de outras marcas. 
Por fim, em relação à qualidade da câmera e sistema operacional (que foram o segundo e terceiro critérios mais votados, respectivamente), vale destacar que as pessoas que mais votaram nesses critérios foram os clientes da Apple (com 47,06\% e 50,94\%, respectivamente), indicando que os smartphones dessa marca possuem essas características na percepção dos seus consumidores (boa qualidade da câmera e bom sistema operacional).

Tabela 1: Critérios Importantes da Decisão de Compra do Consumidor

\begin{tabular}{|l|c|c|}
\hline \multicolumn{3}{|c|}{ Critérios Importantes na Decisão de Compra do Consumidor } \\
\hline & Quantidade de Votos & Percentual de Votos \\
\hline Preço & 71 & $15,64 \%$ \\
\hline Qualidade da Câmera & 68 & $14,98 \%$ \\
\hline Sistema Operacional & 53 & $11,67 \%$ \\
\hline Marca & 45 & $9,91 \%$ \\
\hline Armazenamento & 43 & $9,47 \%$ \\
\hline Processamento & 41 & $9,03 \%$ \\
\hline Memória & 30 & $6,61 \%$ \\
\hline Design do Aparelho & 27 & $5,95 \%$ \\
\hline Funcionalidades Exclusivas & 26 & $5,73 \%$ \\
\hline Tamanho da Tela & 18 & $3,96 \%$ \\
\hline Ecossistema & 8 & $1,76 \%$ \\
\hline Outro & 7 & $1,54 \%$ \\
\hline Assistência Técnica & 6 & $1,32 \%$ \\
\hline Customização & 4 & $0,88 \%$ \\
\hline Garantia & 4 & $0,88 \%$ \\
\hline Prestígio do Fabricante & 3 & $0,66 \%$ \\
\hline Total & 454 & $\mathbf{1 0 0 , 0 0 \%}$ \\
\hline
\end{tabular}

Fonte: Pesquisa de Campo (2019)

\subsection{Lealdade à Marca}

Algumas perguntas foram voltadas para determinar o nível de lealdade que os respondentes possuem ou não com a marca de seu aparelho celular. Para analisar esse tópico, foram levadas em consideração quatro questões: "Há quantos anos você é cliente da marca de seu smartphone?"; "Eu me considero leal à marca de meu smartphone"; "A marca do meu smartphone seria minha primeira opção de compra"; "Eu não vou ser cliente de outra marca de smartphone enquanto a minha estiver disponível".

Em relação à primeira pergunta, mostrada no Gráfico 6, nota-se que a maioria dos respondentes são clientes da mesma marca há mais de 5 anos $(48,89 \%)$ e com isso percebe- 
se que os clientes desse mercado tendem a ser fiéis à marca que usam e não costumam trocar de marca com frequência. Apenas 5,93\% são clientes "novos" de alguma marca (devido ao pouco tempo de fidelidade).

Além disso, destaca-se que dentro dos 66 respondentes que são clientes há mais de 5 anos da mesma marca, 42 são usuários de smartphones da Apple (63,64\%) e 19 (28,79\%) são da Samsung. Com isso, a Apple se mostra como sendo a marca utilizada por mais tempo dentre as pessoas que responderam o questionário, seguida da Samsung, e isso ajuda a explicar o motivo de ambas as marcas serem as mais utilizadas dentre os respondentes. Já a Motorola e a LG possuem o maior número de respondentes na faixa entre 1 e 3 anos de consumo, o que denota que essas marcas não possuem uma alta taxa de retenção de clientes baseado nas respostas coletadas e, portanto, essas duas marcas tenderiam a apresentar maiores dificuldades em atrair novos usuários.

Gráfico 6: Tempo de Uso de Smartphone da mesma Marca, pelos Respondentes

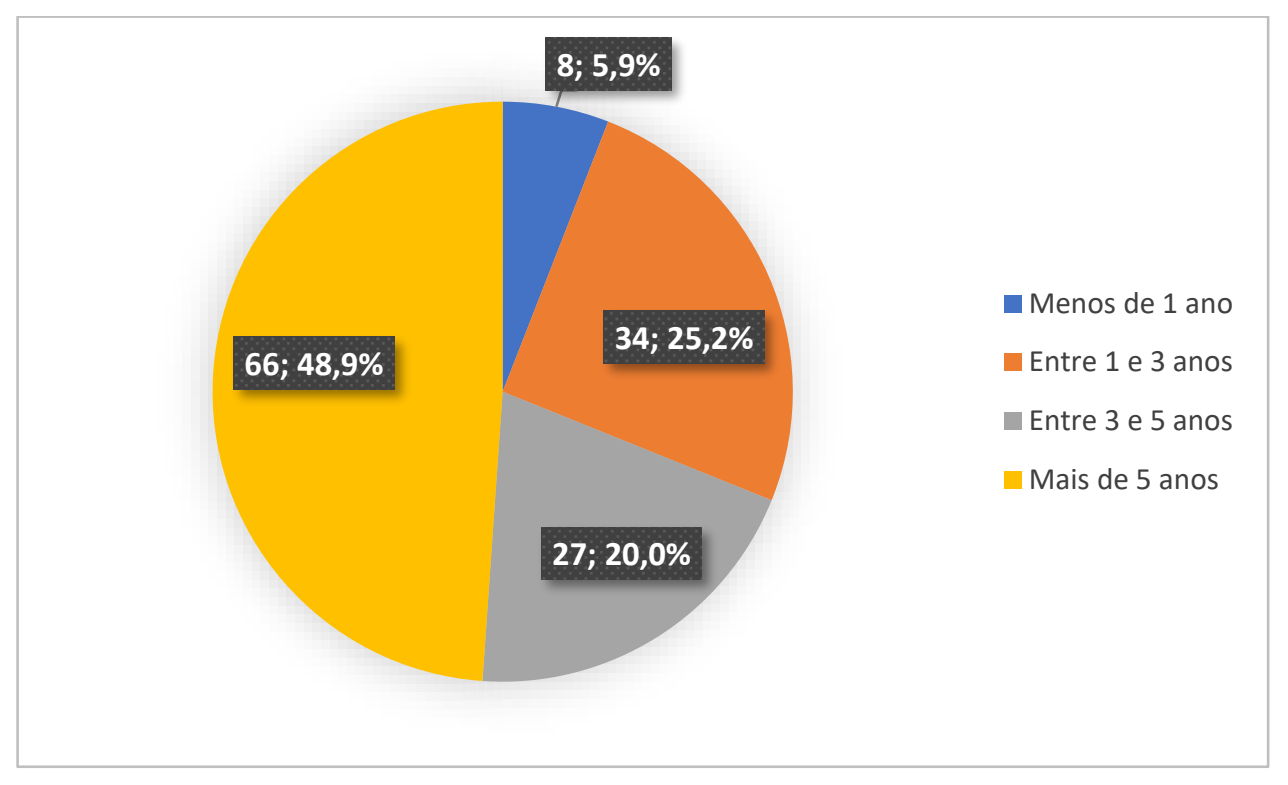

Fonte: Pesquisa de Campo (2019)

Analisando agora a segunda questão sobre fidelidade, mostrada no Gráfico 7, observa-se que $65,93 \%$ da amostra se consideram leais, em algum nível, à sua marca de celular, demonstrando um alto grau de concordância com essa pergunta. Dentre esses, $60,67 \%$ são usuários da Apple e 29,21\% utilizam Samsung, enfatizando que essas são as marcas que possuem clientes com maior nível de fidelidade. Motorola e LG, juntas, somam apenas $10,11 \%$ nesse quesito e seus clientes não se mostram fiéis a elas. 
Gráfico 7: Opinião dos Respondentes em se Considerarem Fiéis a Marca de seu Smartphone

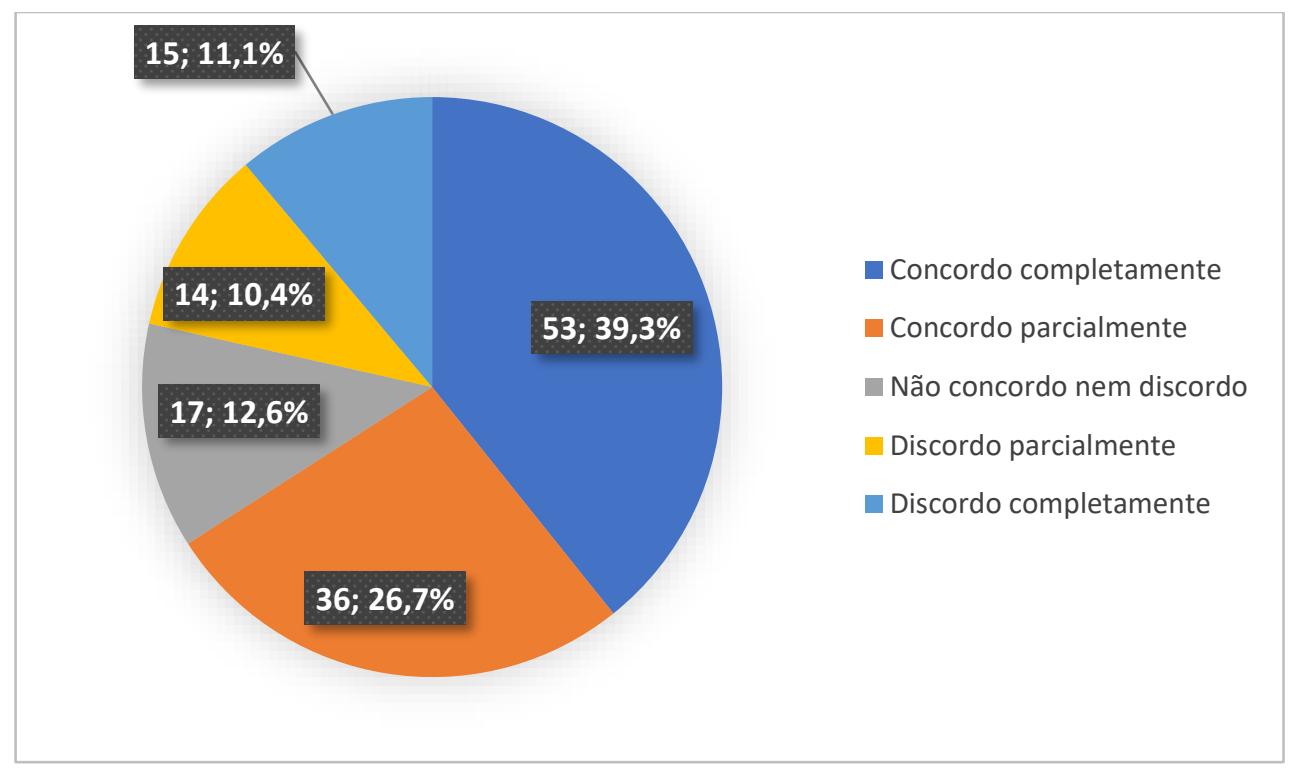

Fonte: Pesquisa de Campo (2019)

Quanto à terceira questão sobre lealdade, podemos notar, segundo o Gráfico 8, que $72,59 \%$ das pessoas concordam, em algum nível, que sua marca de smartphone seria sua primeira opção de compra, provavelmente por se considerarem satisfeitas com a marca que usam. Dentre esses 72,59\%, a maioria são clientes da Apple (59,18\%) e Samsung (30,61\%), enquanto os clientes da Motorola e LG somam 10,20\%. Com isso, a tendência de que a Apple e Samsung possuem os clientes mais leais nesse mercado ganha ainda mais força e isso é reflexo da percepção positiva que os consumidores possuem dessas marcas e da confiança que elas passam para os seus usuários.

Gráfico 8: Opinião dos Respondentes sobre a sua Marca de Smartphone ser sua Primeira Opção de Compra

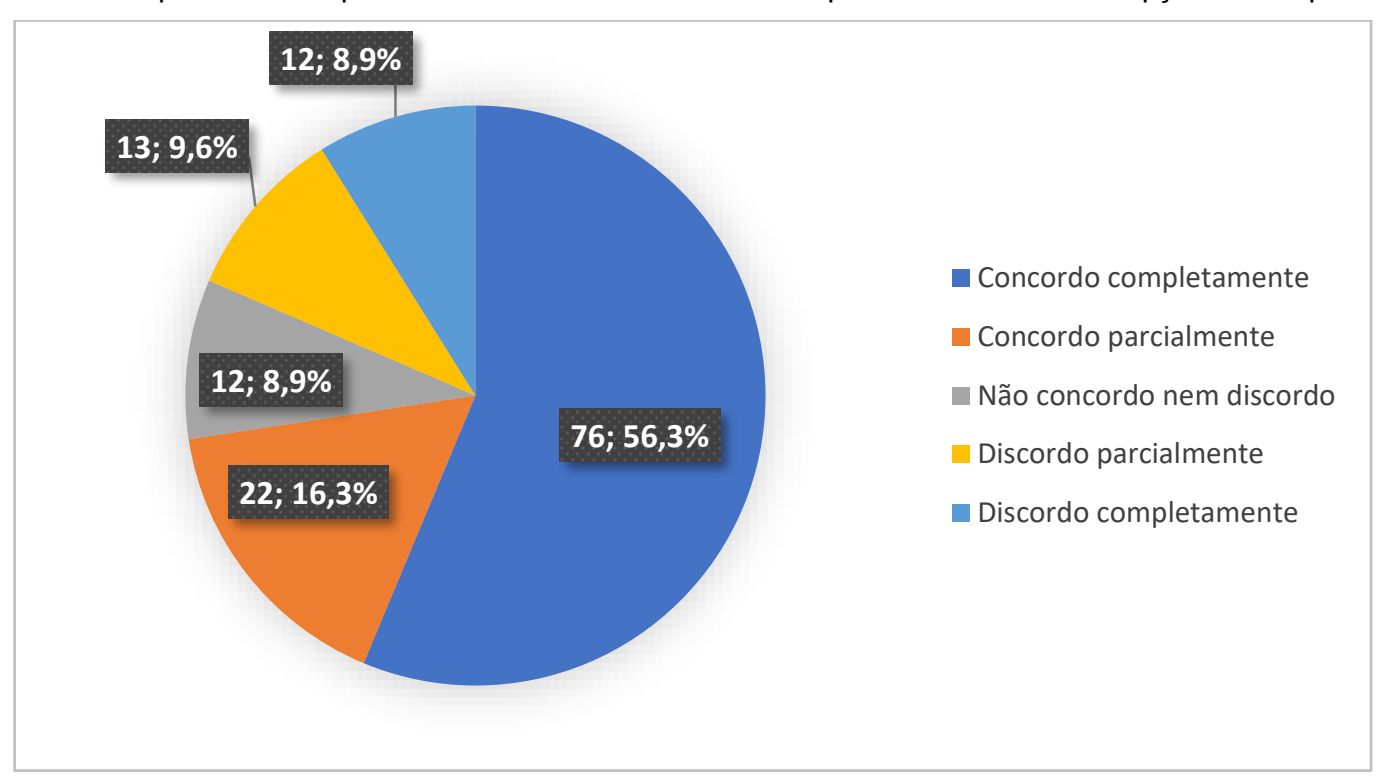


Finalmente, a última pergunta relacionada à lealdade dos respondentes, mostrada no Gráfico 9, demonstra que as respostas variaram bastante, pois não houve nenhuma opção com uma enorme predominância, todas as opções ficaram com percentuais similares. Porém, a opção com maior número de votos foi a de "discordo completamente", mostrando que a maioria dos respondentes discorda completamente da seguinte afirmativa: "Eu não vou ser cliente de outra marca enquanto a minha estiver disponível". Dentre os $28,89 \%$ que votaram nessa opção, a maioria são clientes da Motorola $(41,03 \%)$, o que demonstra que os clientes dessa empresa não possuem uma alta taxa de fidelidade com a marca.

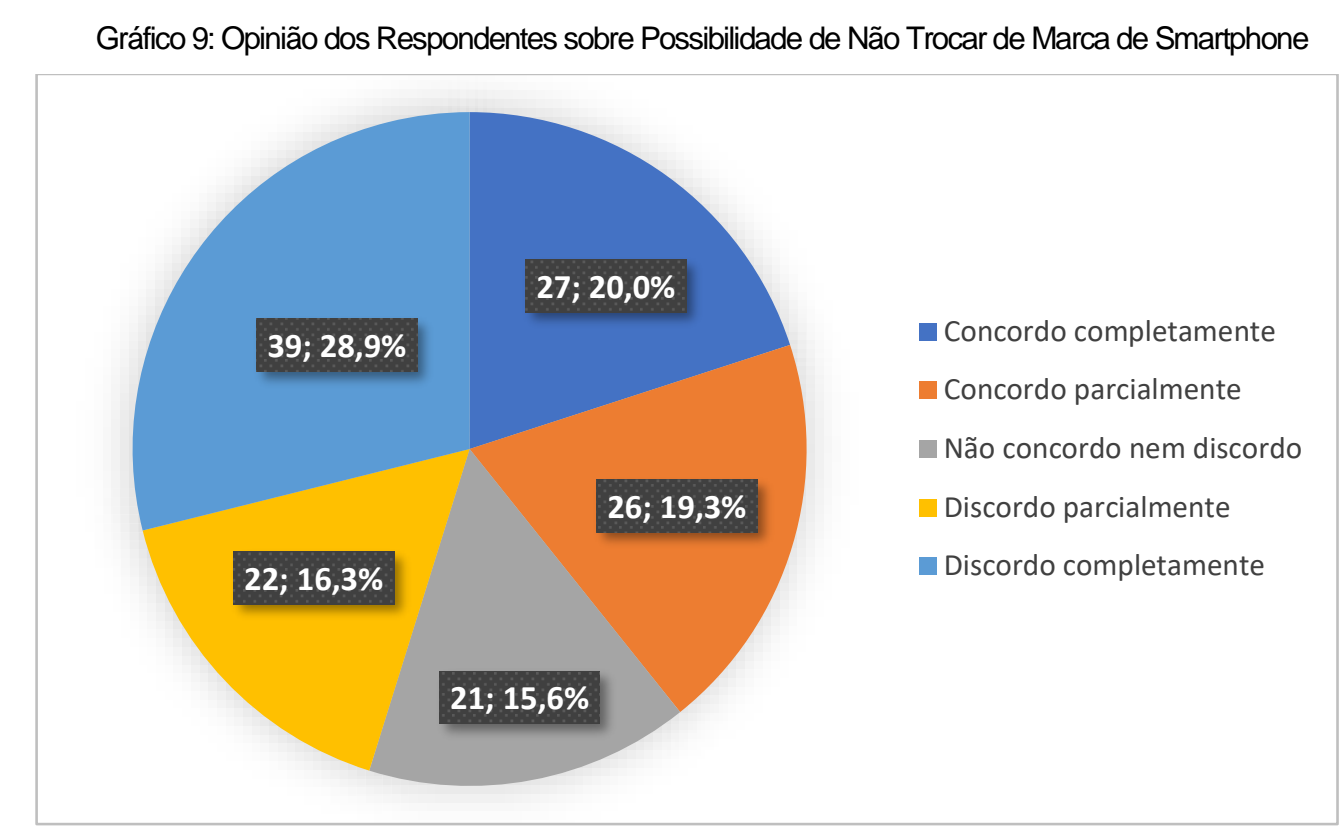

Fonte: Pesquisa de Campo (2019)

\subsection{Qualidade Percebida}

Foi realizada uma pergunta que visava descobrir a qualidade percebida pelos respondentes perante seus smartphones, tal pergunta dizia: "A probabilidade que meu smartphone seja mais vantajoso que o smartphone das demais marcas é bastante alta".

De acordo com o Gráfico 10, podemos observar que 66,67\% dos respondentes concordam, em algum nível, com o fato de que a qualidade de seu smartphone é bastante alta e melhor do que os demais disponíveis no mercado. Desses, $51,11 \%$ são clientes da Apple e $37,78 \%$ da Samsung, o que demonstra que os consumidores dessas marcas entendem que elas fornecem celulares de alta qualidade e que são melhores que os da 
concorrência. A Motorola e LG, possuem 11,11\% dos votos, corroborando a dificuldade dessas marcas em mostrarem as pessoas que seus produtos são de qualidade.

Gráfico 10: Opinião dos Respondentes quanto a Percepção de Qualidade de seu Smartphone

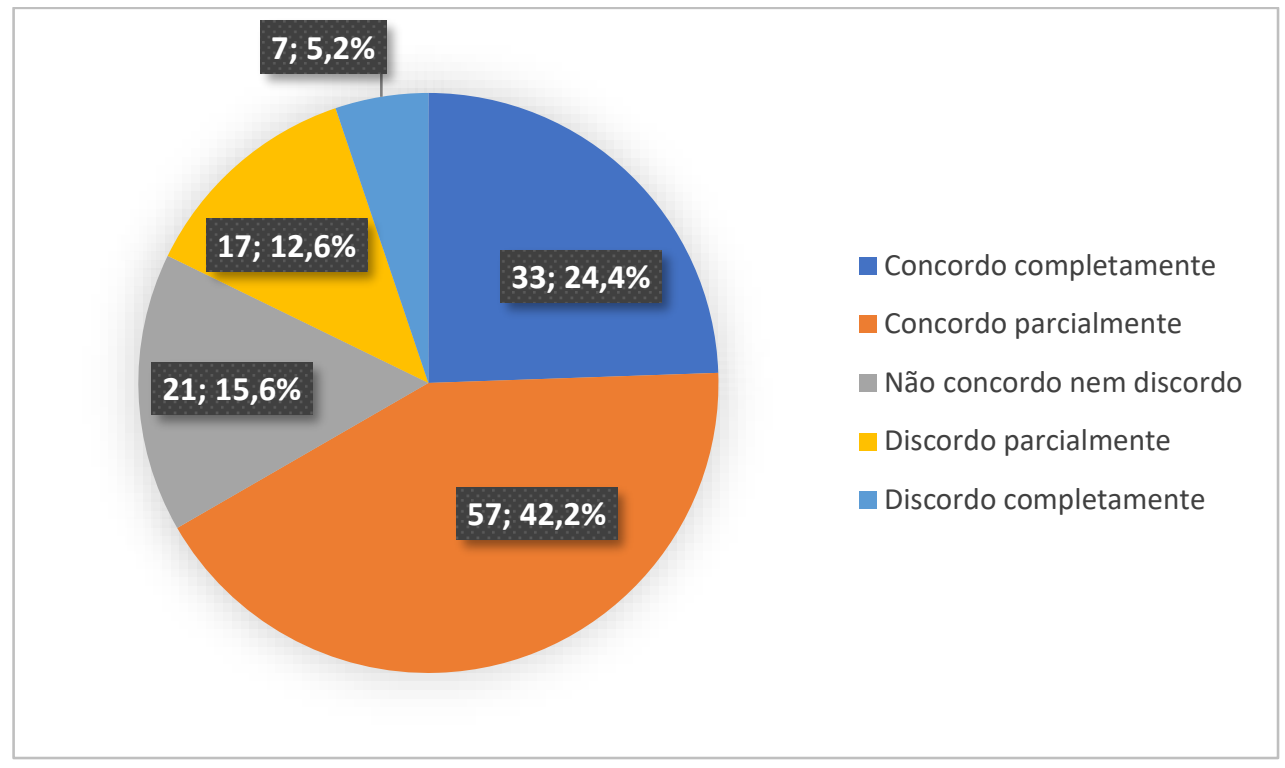

Fonte: Pesquisa de Campo (2019)

\subsection{Associações à Marca}

No que se refere a associações de marca, foram realizadas duas perguntas com o intuito de descobrir se as marcas em questão possuem identidade e imagem fortes ou não no mercado. Para esse tópico, as perguntas utilizadas foram: "Algumas características do meu smartphone vêm à minha mente rapidamente" e "Eu posso me lembrar rapidamente do símbolo ou logo da marca do meu smartphone".

Para a primeira questão, como mostrado no Gráfico 11, o grau de concordância entre as pessoas que a responderam é alto, visto que $81,48 \%$ dos respondentes concordam, em algum nível, que algumas características de seus celulares vêm rapidamente à sua cabeça. É válido ressaltar que, dentre os 60 clientes da Apple que responderam essa pergunta, 57 $(95,00 \%)$ concordam, em algum nível, com essa questão, e isso ressalta como essa marca possui uma identidade forte no mercado e que a mesma é bastante consolidada no mercado. Ademais, dentre os 45 usuários da Samsung que também responderam essa questão, 38 $(84,44 \%)$ também concordam, em algum grau, que lembram de características de seus smartphones. Com isso, pode-se afirmar também que a Samsung possui uma imagem forte de marca e é estabelecida no setor. Já a Motorola e a LG, possuem muito menos 
respondentes que concordam com essa afirmativa, mostrando que essas marcas não foram capazes de construir uma imagem forte a ponto de entrar na memória de seus consumidores.

Gráfico 11: Opinião dos Respondentes sobre Lembrar das Características de seus Smartphones

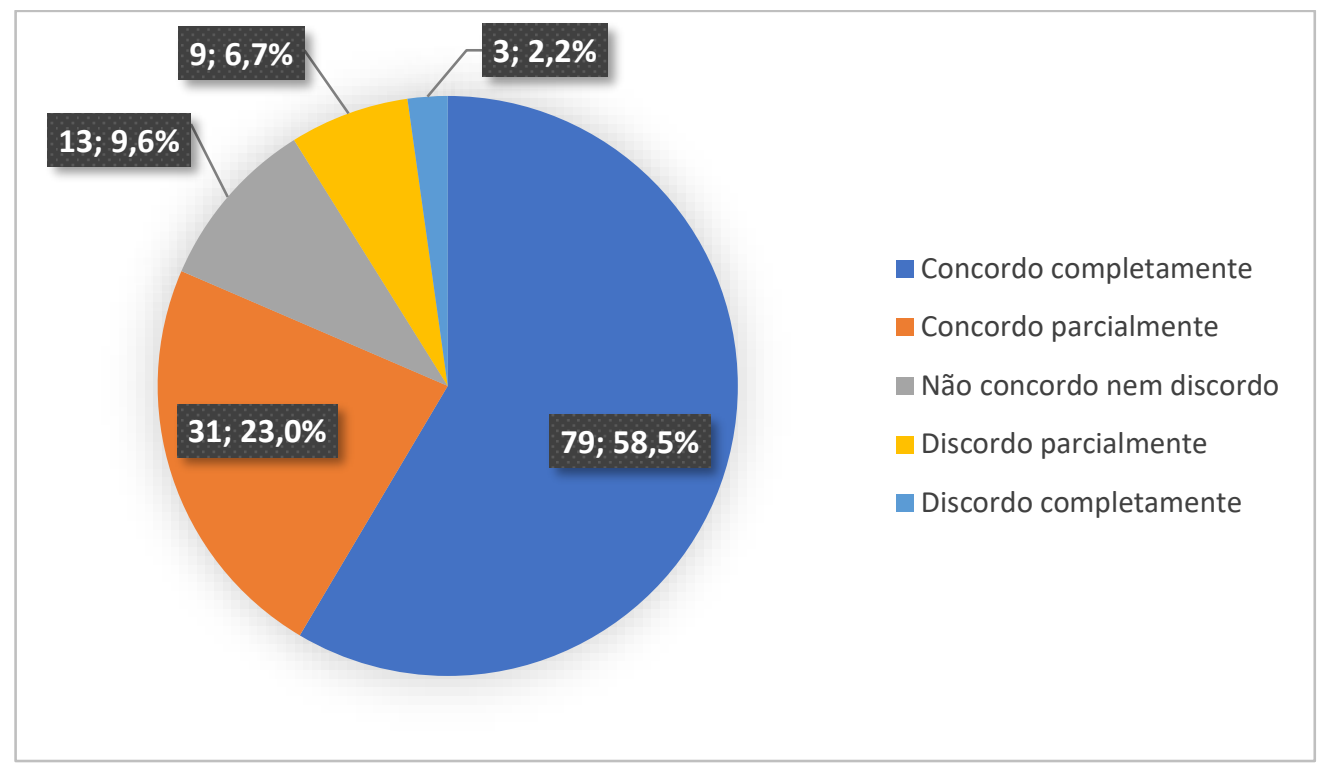

Fonte: Pesquisa de Campo (2019)

Já para a segunda questão, conforme o Gráfico 12, 86,67\% dos respondentes válidos, concordam completamente que conseguem se lembrar rapidamente do logo da marca de seu smartphone. É importante destacar que das 60 respostas dos usuários da Apple, 59 (98,33\%) concordam completamente com isso, mostrando que essa é uma marca muito presente e estabelecida na mente dessas pessoas. Ademais, dos 45 respondentes da Samsung, 34 (75,56\%) concordam totalmente com essa questão, enquanto 19 (76,00\%) dos 25 usuários de Motorola concordam plenamente com isso e por fim, os $5(100 \%)$ respondentes da LG concordam completamente com isso (porém por serem muito poucos respondentes é complexo chegar em uma conclusão definitiva sobre essa marca). 
Gráfico 12: Opinião dos Respondentes sobre a Lembrança do Logo ou Símbolo do seu Smartphone

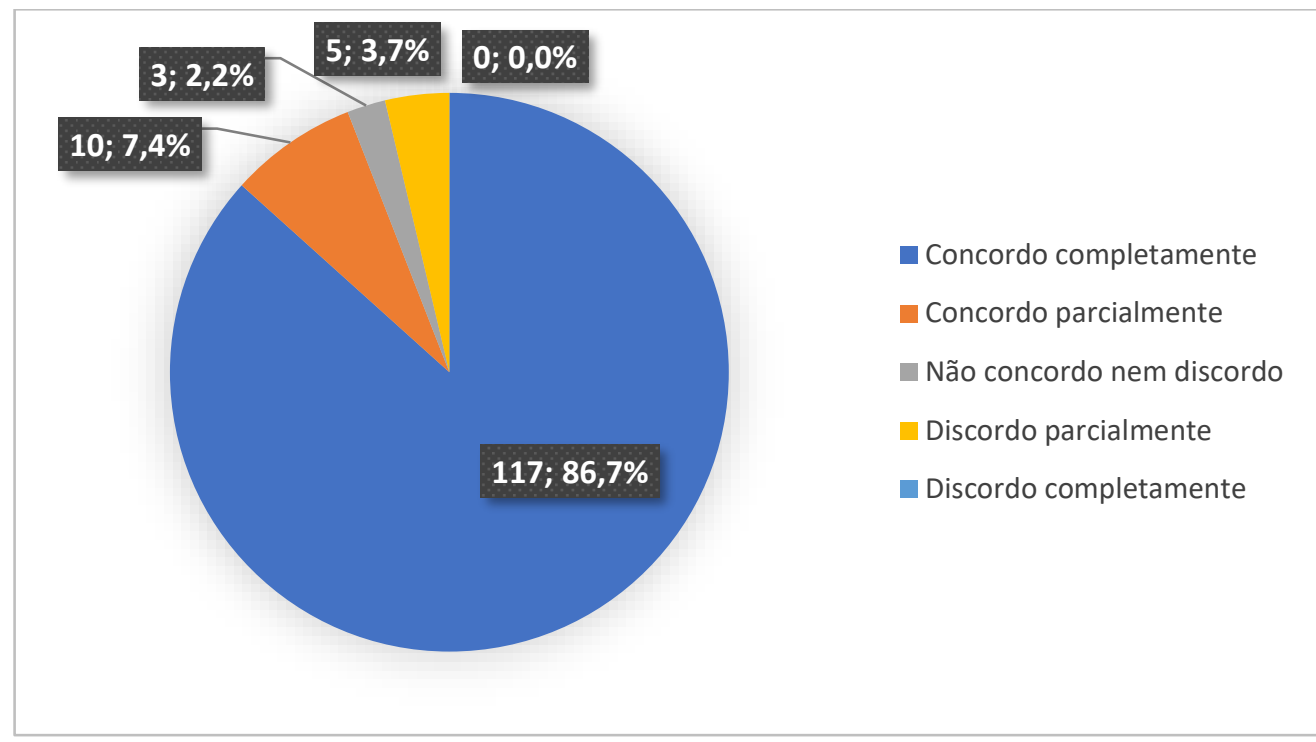

Fonte: Pesquisa de Campo (2019)

\subsection{Conhecimento de Marca}

Para medir o conhecimento de marca, foi realizada uma pergunta referente a isso, que foi a seguinte: "Meus amigos conhecem bem minha marca de smartphone". Com tal questão, pode-se chegar à marca que possivelmente é a top of mind do setor, ou seja aquela que vem em primeiro lugar à mente do consumidor quando pensa nesse setor.

Como pode ser visto no Gráfico $13,82,96 \%$ dos respondentes concordam, em algum nível, que sua marca de smartphone é bem conhecida pelos seus amigos. É de suma importância ressaltar que dentre as 60 respostas de usuários da Apple, 57 (95,00\%) concordam, em algum grau, com essa questão, sendo a marca que possui maior número de clientes que possuem a percepção de que a sua marca é a mais reconhecida no mercado. Com isso, pode-se perceber que a Apple tende a ser a marca mais conhecida nesse setor. 
Gráfico 13: Percepção dos Respondentes sobre Conhecimento da Marca de seu Smartphone

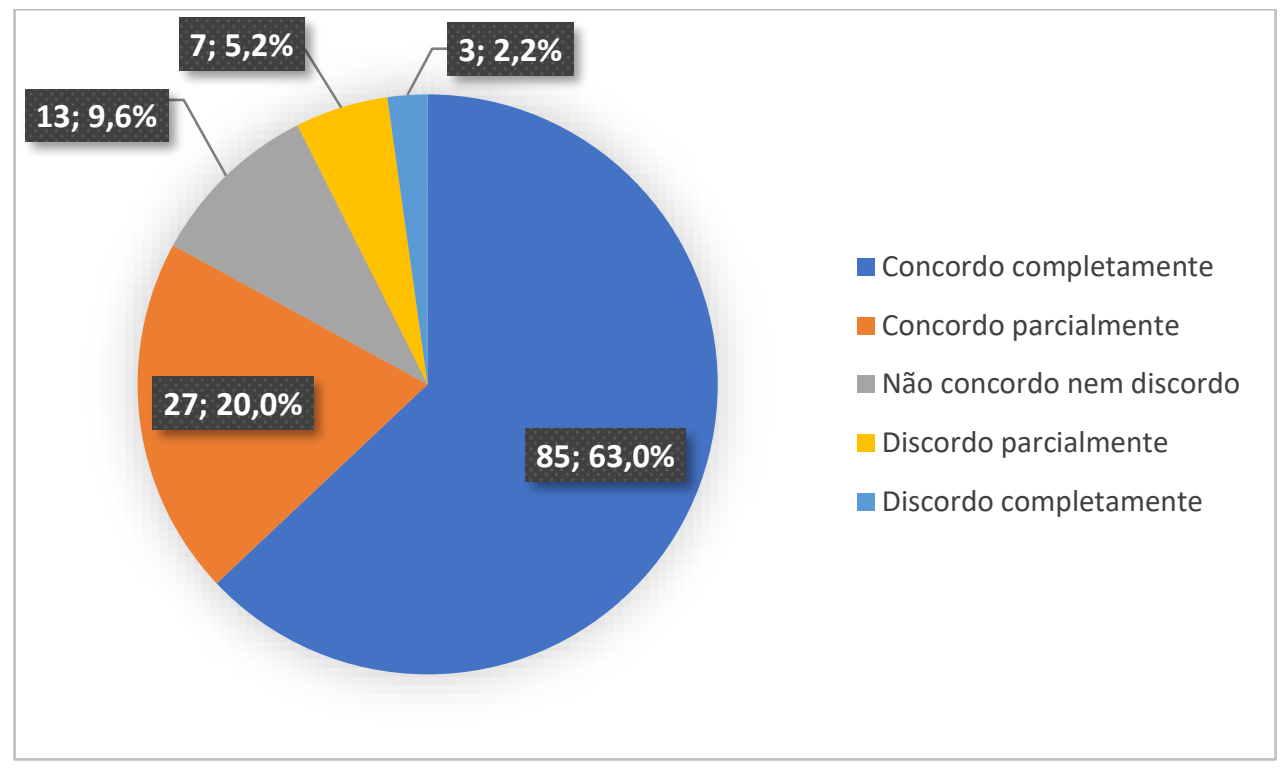

Fonte: Pesquisa de Campo (2019)

\subsection{Avaliação da Importância da Marca}

Por fim, foi realizada uma pergunta que buscava medir a avaliação, por parte dos consumidores, sobre a importância da marca nesse setor. Para tal, foi feita a seguinte pergunta: "Nesse setor, você acredita que a boa avalição da marca é determinante para a compra do smartphone?".

As respostas obtidas, vistas no Gráfico 14, mostram que 97,04\% dos respondentes concordam, em algum grau, que a boa avaliação da marca é determinante para a compra do smartphone, gerando um elevado grau de concordância com essa questão. Isso mostra que as empresas do setor precisam se preocupar em transmitir uma boa imagem e a importância de ser reconhecida como uma marca de qualidade e excelência, visando a se tornar referência na percepção dos consumidores. Dessa forma, ela consegue atingir uma maior base de clientes e uma maior parcela de market share, ou seja, participação de mercado. 
Gráfico 14: Opinião dos Respondentes sobre Importância da Avaliação da Marca no Setor de Smartphones

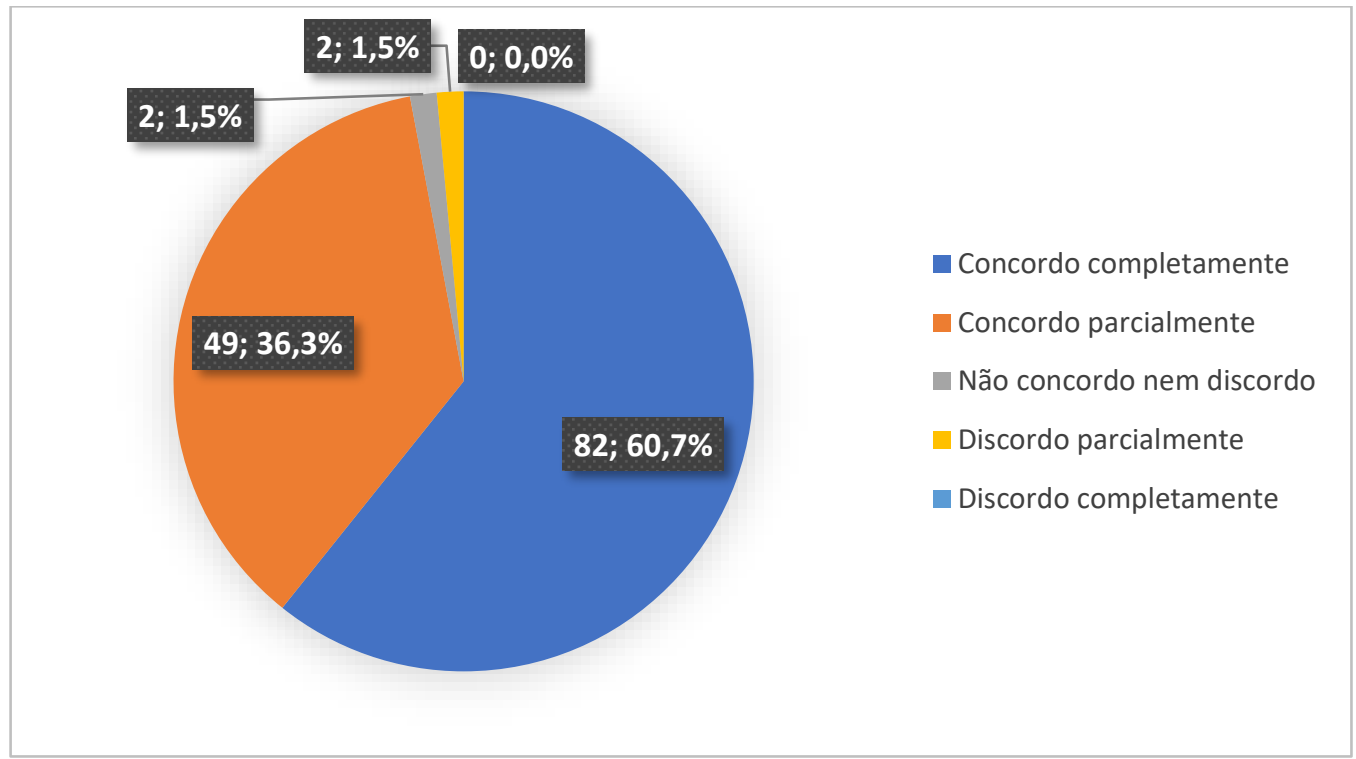

Fonte: Pesquisa de Campo (2019) 


\section{Conclusão}

O principal objetivo do presente trabalho era avaliar o grau de impacto que a marca possui na decisão de compra, na ótica dos consumidores do setor de smartphones, a partir da avaliação do brand equity e também analisar se a marca interfere mais nessa decisão do que as funcionalidades do próprio aparelho celular. Vale ressaltar que a escala MBE, desenvolvida por Yoo e Donthu (2001), aplicada de forma adaptada no questionário, foi de suma importância no alcance desses objetivos, visto que essa escala avalia as dimensões do brand equity por meio de perguntas específicas e ajuda a entender a tomada de decisão dos consumidores.

De acordo com a análise das respostas válidas coletadas no questionário, pode-se afirmar que a Apple é a marca com maior taxa de fidelidade entre os consumidores (enfatizando a importância dada pela marca na busca pela lealdade de seus clientes) e também é, aparentemente, a mais conhecida no mercado em questão, podendo ser a chamada top of mind desse mercado, ao menos entre o público mais jovem, que é o segmento analisado neste estudo. Ademais, os usuários de smartphones da Apple e da Samsung são os que possuem uma maior tendência a serem clientes fiéis e satisfeitos com os smartphones disponibilizados por elas. Isso pode ser explicado, dentre outros fatores, por essas empresas terem construído uma imagem ótima de marca, trabalharem bem sua imagem e também por fabricarem smartphones de alta qualidade percebida. Por outro lado, os clientes da LG e Motorola não se mostram satisfeitos com os produtos fornecidos pela marca, não possuem uma ligação forte com a marca e aparentemente só as utilizam pelo fator preço, o que demonstra que essas duas fabricantes precisam dar uma alta atenção em desenvolver sua marca, visando a captar um maior número de clientes leais, para que, assim, se tornem marcas mais fortes no mercado.

Em relação às implicações gerenciais, é primeiro importante lembrar que ter uma marca consolidada no mercado é um enorme diferencial competitivo, e fortalecer as quatro principais dimensões do brand equity (conhecimento de marca, associações de marca, qualidade percebida e lealdade à marca) é essencial para atingir esse objetivo. Portanto, para que uma marca consiga obter uma boa avaliação entre os consumidores, é de suma importância que ela atente para essas dimensões. 
Com isso, as empresas desse setor precisam se atentar, baseado nos resultados obtidos, em: desenvolver uma marca sólida de mercado; se esforçar para gerar uma alta lembrança e associações de marca na mente dos consumidores; se tornar bastante conhecida pelas pessoas; produzir produtos com uma alta qualidade percebida; e conseguir atrair e reter o maior número possível de clientes leais. Dessa forma, as empresas no setor de smartphones devem fazer o possível par aprimorar todos os pontos citados anteriormente com o intuito de se tornarem marcas fortes no mercado.

Em suma, percebe-se que o objetivo principal do trabalho foi devidamente analisado e cumprido, uma vez que, por meio da análise de dados, observou-se que a marca possui um alto grau de impacto na decisão de compra dos consumidores e interfere mais do que muitas funcionalidades do próprio smartphone, no momento da compra. Ademais, os objetivos intermediários também foram alcançados e analisados.

Por fim, para trabalhos futuros sobre esse assunto, recomenda-se que sejam feitas pesquisas que incluam outras marcas além das que foram contempladas neste trabalho, visando estudar a opinião dos consumidores de outras marcas em relação ao grau de impacto que eles acreditam que a marca possui no processo decisório de compra. Ademais, sugerese que sejam incluídas, em novas pesquisas, outras escalas de medição de valor de marca. 


\section{Referências Bibliográficas}

AAKER, D. A. Building Strong Brands. New York: The Free Press, 1996.

AAKER, D. A. Managing Brand Equity. New York: The Free Press, 1991.

AAKER, D. A. Marcas: Brand Equity gerenciando o valor da marca: 3 ed. São Paulo: Negócio Editora, 1998.

AGRELA, L. Apple é a marca de smartphones preferida dos brasileiros. Disponível em: $<$ https://exame.abril.com.br/tecnologia/apple-e-a-marca-de-smartphones-preferida-dosbrasileiros/>. Acesso em: 12 set. 2019.

BBC. Por que a classe média está ficando muito endividada em vários lugares do mundo, segundo a OCDE. Disponível em: <https://g1.globo.com/economia/noticia/2019/04/10/por-que-a-classe-media-ficando-muitoendividada-em-varios-lugares-do-mundo-segundo-a-ocde.ghtml>. Acesso em: 16 de out. 2019.

BENNETT, P. D. O Comportamento do Consumidor: 2 ed. São Paulo: Atlas, 1980.

BRAND FINANCE. Brand Finance Global 500 2019. Disponível em: $<\mathrm{https}: / /$ brandfinance.com/knowledge-centre/reports/brand-finance-global-500-2019/>. Acesso em: 12 set. 2019.

BRIGATTO, G. Samsung do Brasil fatura $\mathbf{R} \boldsymbol{\$} 23$ bilhões. Disponível em: <https://www.valor.com.br/empresas/6157779/samsung-do-brasil-fatura-r-23-bilhoes>. Acesso em: 11 set. 2019.

CHURCHILL, G.; PETER, J. Marketing: Criando Valor para os Clientes: 3 ed. São Paulo: Saraiva, 2012.

ENGEL, J. F.; BLACKWELL, R. D.; MINIARD, P. W. Comportamento do Consumidor: 8 ed. Rio de Janeiro: Livros Técnicos e Científicos Editora, 2000.

GOVERNO FEDERAL. DECRETO № 9.661, DE 1 DE JANEIRO DE 2019. Disponível em: <http://www.planalto.gov.br/ccivil_03/_Ato2019-2022/2019/Decreto/D9661.htm>. Acesso em: 19 out. 2019. 
IBGE. IBGE divulga as estimativas da população dos municípios para 2019. Disponível em: <https://agenciadenoticias.ibge.gov.br/agencia-sala-de-imprensa/2013-agencia-denoticias/releases/25278-ibge-divulga-as-estimativas-da-populacao-dos-municipios-para2019>. Acesso em: 28 set. 2019.

JAMIESON, S. Likert scale. Disponível em: <https://www.britannica.com/topic/Likert-Scale>. Acesso em: 28 set. 2019.

KAPFERER, J. N. O que vai mudar as marcas. Porto Alegre: Bookman, 2004.

KELLER, K. Bulding Costumer-Based Brand Equity: A Blueprint for Creating Strong Brands. Marketing Science Institute, Working Paper Series, 2001.

KELLER, K. Conceptualizing, Measuring, and Managing Customer-Based Brand Equity. Journal of Marketing, 1993.

KELLER, K.; MACHADO, M. Gestão Estratégica de Marcas: São Paulo: Pearson, 2006.

KOHLI, C.; LEUTHESSER, L. Brand equity: capitalizing on intellectual capital: London: Ivey Business Journal, 2001.

KOTLeR, P.; ARMStRONG, G. Princípios de Marketing: 12 ed. São Paulo: Prentice Hall, 2003.

KOTLER, P.; KELLER, K. Administração de Marketing: 14 ed. São Paulo: Pearson, 2012.

OGAWA, M. Global Mobile Consumer Survey 2018. Disponível em: $<$ https://www2.deloitte.com/br/pt/pages/technology-media-and-

telecommunications/articles/mobile-survey.html>. Acesso em: 12 jun. 2019.

RAMOS, C.; RODRIGUES, N.; PICILLO, G. IAB Brasil lança infográfico sobre hábitos no ambiente mobile. Disponível em: <https://iabbrasil.com.br/iab-brasil-lanca-infografico-sobrehabitos-no-ambiente-mobile/>. Acesso em: 12 set. 2019.

RAOSOFT. Sample size calculator. Disponível em: <http://www.raosoft.com/samplesize.html>. Acesso em: 28 set. 2019.

SCHIFFMAN, L. G.; KANUK, L. L. Comportamento do Consumidor: 6 ed. Rio de Janeiro: Livros Técnicos e Científicos, 2000.

SERRA, E. M., GONZALEZ, J. A. V. A Marca: Avaliação e Gestão Estratégica. Lisboa: Editora Verbo, 1998.

SHARMA, P. Brazil Smartphone Market Shows Signs of Recovery. Disponível em: $<$ https://www.counterpointresearch.com/brazil-smartphone-market-shows-positive-signs- 
recovery/?utm_source=bdi\&utm_medium=brazil\&utm_content=statistic $>$. Acesso em: 12 jun. 2019.

SOLOMON, M. O Comportamento do Consumidor: comprando, possuindo e sendo: 9 ed. Porto Alegre: Bookman, 2011.

STATCOUNTER. Mobile Vendor Market Share Brazil. Disponível em: <http://gs.statcounter.com/vendor-market-share/mobile/brazil>. Acesso em: 26 abr. 2019.

VERGARA, S. C. Projetos e Relatórios de Pesquisa em Administração: 3 ed. São Paulo: Atlas, 2000.

YOO, B.; DONTHU, N. Developing and validating a multidimensional consumer-based brand equity scale. Journal of Business Research, 2001.

YOO, B.; DONTHU, N.; LEE, S. An examination of selected marketing mix elements and brand equity. Journal of the Academy of Marketing Science, 2000. 


\section{Anexo 1}

\section{As marcas no setor de smartphones.}

Agradeço sua participação no questionário que elaborei para meu projeto de monografia.

Tenha em mente que não existem respostas certas ou erradas, apenas opiniões. Ademais, esta pesquisa é 100\% anônima.

Vale também destacar que após responder uma pergunta, não será possível alterar sua resposta.

Por Pedro H. Salles

Qual é a marca do seu smartphone?
Apple
O LG
Motorola
Samsung
Outro (especifique)

Há quantos anos você é cliente da marca do seu atual smartphone?
Menos de 1 ano
Entre 1 e 3 anos
Entre 3 e 5 anos
Mais de 5 anos 
Nas questões a seguir, marque a opção que melhor descreve a sua opinião em relação as afirmativas descritas.

Eu me considero leal à marca de meu smartphone.

Concordo completamente

Concordo parcialmente

Não concordo nem discordo

Discordo parcialmente

Discordo completamente

A marca do meu smartphone seria minha primeira opção de compra.

Concordo completamente

Concordo parcialmente

Não concordo nem discordo

Discordo parcialmente

$\bigcirc$ Discordo completamente

Eu não vou ser cliente de outra marca de smartphone enquanto a minha estiver disponível.

Concordo completamente

Concordo parcialmente

Não concordo nem discordo

Discordo parcialmente

Discordo completamente

A probabilidade que meu smartphone seja mais vantajoso que os smartphones das demais marcas é bastante alta.
Concordo completamente
Concordo parcialmente
Não concordo nem discordo
Discordo parcialmente
Discordo completamente

Meus amigos conhecem bem a minha marca de smartphone.

Concordo completamente

Concordo parcialmente

Não concordo nem discordo

Discordo parcialmente

Discordo completamente 
Algumas características da marca do meu smartphone vêm à minha mente rapidamente.

Concordo completamente

Concordo parcialmente

Não concordo nem discordo

Discordo parcialmente

Discordo completamente

Eu posso me lembrar rapidamente do símbolo ou logo da marca do meu smartphone.

Concordo completamente

Concordo parcialmente

Não concordo nem discordo

Discordo parcialmente

Discordo completamente

Quais são os critérios que você considera mais importantes para decidir qual smartphone comprar?

$\square$ Marca

$\square$ Preço

$\square$ Funcionalidades Exclusivas

$\square$ Processamento

Armazenamento

$\square$ Memória

Qualidade da Câmera

$\square$ Ecossistema (acessórios da marca para completar o celular, como: smartwatch, fone de ouvido, etc)

$\square$ Design do Aparelho

$\square$ Customização

$\square$ Sistema Operacional (iOS,Android,etc)

$\square$ Garantia

Assistência Técnica

$\square$ Prestígio do Fabricante

Tamanho da Tela

$\square$ Outro (especifique) 
Nesse setor, você acredita que a boa avaliação da marca é determinante para a compra do smartphone?
Concordo completamente
Concordo parcialmente
Não concordo nem discordo
Discordo parcialmente
Discordo completamente

\section{Perfil do respondente.}

Estamos quase no final! Peço apenas que responda as seguintes questões sobre você.

Desde já, agradeço!

Qual sua idade?

Menos de 18 anos

Ontre 18 e 24 anos

Entre 25 e 31 anos

Entre 32 e 38 anos

Ontre 39 e 45 anos

Entre 46 e 52 anos

Mais que 52 anos

Qual seu sexo?

Masculino

Feminino

Qual seu grau de escolaridade?

Ensino médio incompleto/cursando

Ensino médio completo

Ensino superior incompleto/cursando

O Ensino superior completo

Pós-graduação incompleta/cursando 
Pós-graduação completa

Qual sua renda familiar mensal (somando a renda de todos que moram com você)?

Até $\mathrm{R} \$ 1.996,00$

De $R \$ 1.996,01$ até $R \$ 3.992,00$

De $R \$ 3.992,01$ até $R \$ 9.980,00$

De $R \$ 9.980,01$ até $R \$ 19.960,00$

O Acima de $\mathrm{R} \$ 19.960,01$ 
Anexo 2

\section{Multidimensional Brand Equity (MBE) Scale}

\section{Brand loyalty}

- I consider myself to be loyal to $X$.

- $X$ would be my first choice.

- I will not buy other brands if $X$ is avaliable at the store.

\section{Perceived quality}

- The likely quality of $X$ is extremely high.

- The likelihood that $X$ would be functional is very high.

\section{Brand awaraness/associations}

- I can recognize $X$ among other competing brands.

- I am aware of $X$.

- Some characteristics of X come to my mind quickly.

- I can quickly recall the symbol or logo of $X$.

- I have difficult in imagining $X$ in my mind. 